University of Nebraska - Lincoln

DigitalCommons@University of Nebraska - Lincoln

$3-31-2011$

\title{
Transformation of Hexahydro-1,3,5-trinitro-1,3,5-triazine (RDX) by Permanganate
}

\author{
Chanat Chokejaroenrat \\ University of Nebraska-Lincoln \\ Steven Comfort \\ University of Nebraska - Lincoln, scomfort1@unl.edu \\ Clifford E. Harris \\ Albion College \\ Daniel D. Snow \\ University of Nebraska-Lincoln, dsnow1@unl.edu \\ David A. Cassada \\ University of Nebraska-Lincoln, dcassada1@unl.edu \\ See next page for additional authors
}

Follow this and additional works at: https://digitalcommons.unl.edu/watercenterpubs

Part of the Water Resource Management Commons

Chokejaroenrat, Chanat; Comfort, Steven; Harris, Clifford E.; Snow, Daniel D.; Cassada, David A.; Sakulthaew, Chainarong; and Satapanajaru, Tunlawit, "Transformation of Hexahydro-1,3,5-trinitro-1,3,5-triazine (RDX) by Permanganate" (2011). Faculty Publications from The Water Center. 22.

https://digitalcommons.unl.edu/watercenterpubs/22

This Article is brought to you for free and open access by the Water Center, The at DigitalCommons@University of Nebraska - Lincoln. It has been accepted for inclusion in Faculty Publications from The Water Center by an authorized administrator of DigitalCommons@University of Nebraska - Lincoln. 


\section{Authors}

Chanat Chokejaroenrat, Steven Comfort, Clifford E. Harris, Daniel D. Snow, David A. Cassada, Chainarong Sakulthaew, and Tunlawit Satapanajaru 


\title{
Transformation of Hexahydro-1,3,5-trinitro-1,3,5-triazine (RDX) by Permanganate
}

\author{
Chanat Chokejaroenrat, ${ }^{1}$ Steve D. Comfort, ${ }^{2}$ Clifford E. Harris, ${ }^{3}$ Daniel D. Snow, ${ }^{4}$ \\ David Cassada, ${ }^{4}$ Chainarong Sakulthaew ${ }^{2,5}$ and Tunlawit Satapanajaru ${ }^{6}$
}

1. Department of Civil Engineering, University of Nebraska-Lincoln, Lincoln, Nebraska 68588-0531, USA

2. School of Natural Resources, University of Nebraska-Lincoln, Lincoln, Nebraska 68583-0915, USA

3. Department of Chemistry, Albion College, Albion, Michigan 49224, USA

4. Water Sciences Laboratory, University of Nebraska-Lincoln, Lincoln, Nebraska 68583-0844, USA

5. Department of Veterinary Technology, Kasetsart University, Bangkok, Thailand 10900

6. Department of Environmental Science, Kasetsart University, Bangkok, Thailand 10900

Corresponding author - S. D. Comfort, tel 402 472-1502, fax 402 472-7904, email scomfort@unl.edu

\begin{abstract}
The chemical oxidant permanganate $\left(\mathrm{MnO}_{4}^{-}\right)$has been shown to effectively transform hexahydro-1,3,5-trinitro-1,3,5-triazine (RDX) at both the laboratory and field scales. We treated RDX with $\mathrm{MnO}_{4}^{-}$with the objective of quantifying the effects of $\mathrm{pH}$ and temperature on destruction kinetics and determining reaction rates. A nitrogen mass balance and the distribution of reaction products were used to provide insight into reaction mechanisms. Kinetic experiments (at pH $\sim 7,25$ ${ }^{\circ} \mathrm{C}$ ) verified that $\mathrm{RDX}-\mathrm{MnO}_{4}{ }^{-}$reaction was first-order with respect to $\mathrm{MnO}_{4}^{-}$and initial RDX concentration (second-order rate: $4.2 \times 10^{-5} \mathrm{M}^{-1} \mathrm{~s}^{-1}$ ). Batch experiments showed that choice of quenching agents $\left(\mathrm{MnSO}_{4}, \mathrm{MnCO}_{3}\right.$, and $\left.\mathrm{H}_{2} \mathrm{O}_{2}\right)$ influenced sample $\mathrm{pH}$ and product distribution. When $\mathrm{MnCO}_{3}$ was used as a quenching agent, the $\mathrm{pH}$ of the $\mathrm{RDX}-\mathrm{MnO}_{4}^{-}$solution was relatively unchanged and $\mathrm{N}_{2} \mathrm{O}$ and $\mathrm{NO}_{3}{ }^{-}$constituted $94 \%$ of the $\mathrm{N}$-containing products after $80 \%$ of the RDX was transformed. On the basis of the preponderance of $\mathrm{N}_{2} \mathrm{O}$ produced under neutral $\mathrm{pH}$ (molar ratio $\mathrm{N}_{2} \mathrm{O} / \mathrm{NO}_{3} \sim 5: 1$ ), no strong $\mathrm{pH}$ effect on $\mathrm{RDX}-\mathrm{MnO}_{4}{ }^{-}$reaction rates, a lower activation energy than the hydrolysis pathway, and previous literature on $\mathrm{MnO}_{4}^{-}$oxidation of amines, we propose that $\mathrm{RDX}-\mathrm{MnO}_{4}^{-}$reaction involves direct oxidation of the methylene group (hydride abstraction), followed by hydrolysis of the resulting imides, and decarboxylation of the resulting carboxylic acids to form $\mathrm{N}_{2} \mathrm{O}, \mathrm{CO}_{2}$, and $\mathrm{H}_{2} \mathrm{O}$.
\end{abstract}

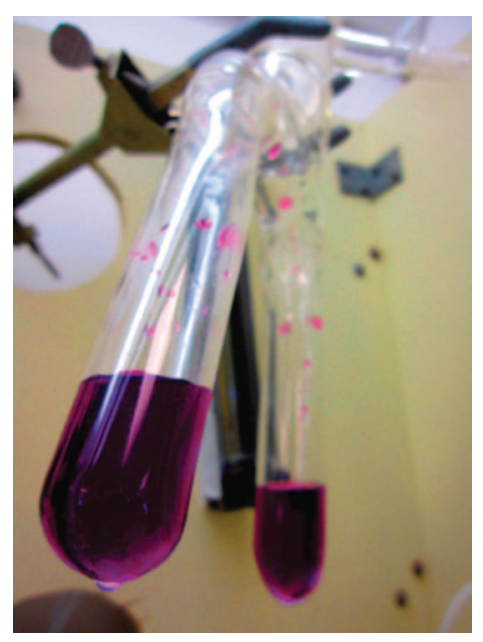

\section{Introduction}

Hexahydro-1,3,5-trinitro-1,3,5-triazine (RDX) is a common groundwater contaminant at numerous military sites where munitions were either formulated, manufactured, or used in military exercises. Permanganate $\left(\mathrm{MnO}_{4}^{-}\right)$is an oxidant commonly used with in situ chemical oxidation (ISCO) and has been widely accepted for treating chlorinated ethenes. Past research has shown that $\mathrm{MnO}_{4}^{-}$preferentially attacks compounds with carbon-carbon double bonds, aldehyde groups, or hydroxyl groups and is attracted to the electron-rich region of chlorinated alkenes.(1) Although RDX possesses none of these characteristics, laboratory studies performed by Adam et al.(2) showed that $\mathrm{MnO}_{4}{ }^{-}$could effectively transform and mineralize RDX (i.e., $\sim 87 \%$ recovered as ${ }^{14} \mathrm{CO}_{2}$ ). Moreover, a pilotscale demonstration at the Nebraska Ordnance Plant further supported $\mathrm{MnO}_{4}{ }^{-}$as a possible in situ treatment for RDX-contaminated groundwater.(3) Despite demonstrating efficacy in removing RDX from tainted waters, the reaction rates and mechanisms by which $\mathrm{MnO}_{4}^{-}$transforms RDX (and other explosives) have not been thoroughly studied.(4) While a carbon mass balance of the $\mathrm{RDX}-\mathrm{MnO}_{4}{ }^{-}$reaction has been observed,(2) a similar nitrogen mass balance for this reaction has not been reported.

One analytical challenge to identifying degradation products in a $\mathrm{MnO}_{4}^{-}$matrix is that the solution is highly colored (i.e., purple), so colorimetric and UV detection techniques are not possible unless samples are quenched to remove $\mathrm{MnO}_{4}{ }^{-}$ before analysis. However, the choice of quenching agent may influence $\mathrm{pH}$ or product distribution and further complicates understanding the $\mathrm{RDX}-\mathrm{MnO}_{4}{ }^{-}$reaction mechanism.

The transformation of RDX by various treatments has revealed several possible reaction pathways. These include direct ring cleavage, nitro-group reduction, concerted decomposition, and N-denitration.(5-12) While intermediates produced by some of these pathways are fleeting and difficult to mea- 
sure, the end products produced are often similar $\left(\mathrm{N}_{2} \mathrm{O}, \mathrm{NO}_{2}^{-}\right.$, $\mathrm{NO}_{3}^{-}, \mathrm{NH}_{4}^{+}$) but produced in different ratios depending on the reaction mechanisms. In this paper, we report results from laboratory investigations designed to describe the kinetics of the $\mathrm{RDX}-\mathrm{MnO}_{4}^{-}$interaction, quantify the effect of temperature on RDX destruction kinetics, and provide a nitrogen mass balance of the $\mathrm{RDX}-\mathrm{MnO}_{4}{ }^{-}$reaction. On the basis of experimental results, possible mechanisms by which RDX is degraded by $\mathrm{MnO}_{4}^{-}$are proposed.

\section{Experimental Section}

Details of the chemical standards, analytical instruments (e.g., HPLC, IC, GC/ECD, and UV spectrophotometer), analysis of $\mathrm{N}$-containing gases, RDX purification procedures used for mass balance experiments, and experimental controls are provided in Supporting Information (SI-1, SI-2, SI-3).

Aliquot Sample Preparation. To accurately quantify RDX and degradation product concentrations during oxidation by $\mathrm{MnO}_{4}^{-}$, samples were quenched to prevent further RDX transformation. To avoid interferences during RDX and degradate analyses, three different quenching agents were tested $\left(\mathrm{MnSO}_{4}, \mathrm{MnCO}_{3}\right.$, and $\left.\mathrm{H}_{2} \mathrm{O}_{2}\right)$. The choice of quenching agent was found to influence $\mathrm{pH}$ and product distribution (see Supporting Information, SI-4). The two quenching agents we used most frequently included $\mathrm{MnCO}_{3}(0.10 \mathrm{~g}$ per $\mathrm{mL}$ of sample unless otherwise stated) and $\mathrm{MnSO}_{4} \cdot \mathrm{H}_{2} \mathrm{O}[0.10 \mathrm{~mL}$ of a $\mathrm{MnSO}_{4}$ solution $(0.10 \mathrm{~g} / \mathrm{mL})$ per $\mathrm{mL}$ of sample]. The typical quenching procedure involved removing 1-mL aliquots from the $\mathrm{RDX}-\mathrm{MnO}_{4}{ }^{-}$batch reactors, placing the aliquots in a 1.5- $\mathrm{mL}$ centrifuge tube, adding the quenching agent, and centrifuging at $14000 \mathrm{rpm}$ for $10 \mathrm{~min}$. When $\mathrm{MnCO}_{3}$ was used, an addition $5 \mathrm{~min}$ of shaking on a vortex was performed before centrifuging. The supernatant was then transferred to an HPLC or an IC vial and stored at $4{ }^{\circ} \mathrm{C}$ until analysis.

RDX Kinetic Experiments. Kinetic experiments were performed under batch conditions by placing $150 \mathrm{~mL}$ of RDX solution in 250-mL Erlenmeyer flasks and agitating on an orbital shaker. Solution samples were taken every $2-3 \mathrm{~d}$, quenched with $\mathrm{MnSO}_{4}$, and analyzed for RDX by HPLC. We initially prepared RDX solutions by spiking $150 \mathrm{~mL}$ of $\mathrm{H}_{2} \mathrm{O}$ with $1.04 \mathrm{~mL}$ of RDX stock solutions prepared in acetone, but acetone was found to facilitate the decomposition of $\mathrm{MnO}_{4}^{-}$ at alkaline $\mathrm{pH}$ and prevent further degradation of $\mathrm{RDX}>10 \mathrm{~d}$ (see Supporting Information, SI-5). Consequently, all aqueous RDX solutions were prepared by dissolving purified crystalline RDX in water over several days.

To determine reaction rates, kinetic experiments fixed the initial RDX concentration at $0.09 \mathrm{mM}$ and samples were treated with $\mathrm{MnO}_{4}^{-}$in excess by varying concentrations between 4.20 and $84.03 \mathrm{mM}$. Likewise, using initial $\mathrm{MnO}_{4}{ }^{-}$concentrations at $33.61 \mathrm{mM}$, we treated varying concentrations of RDX (0.01-0.09 $\mathrm{mM})$. Both experiments were conducted in neutral $\mathrm{pH}(\sim 7)$ at room temperature $\left(25^{\circ} \mathrm{C}\right)$. Reaction rates were then determined by the initial rate method.(13) The rate law describing a second-order reaction between RDX and $\mathrm{MnO}_{4}^{-}$is presented in Supporting Information (SI-6).

RDX- $\mathrm{MnO}_{4}{ }^{-}$Temperature Experiment. To quantify the effect of temperature on the $\mathrm{RDX}-\mathrm{MnO}_{4}{ }^{-}$reaction (i.e., second-order rate constant, $k^{\prime \prime}$ ), we performed experiments in 150-mL glass bottles containing $100 \mathrm{~mL}$ of RDX $(0.02$ $m \mathrm{M})$. Treatment temperatures were $20,35,50$, and $65^{\circ} \mathrm{C}$ and held constant for $2-3 \mathrm{~h}$ prior to the start of the experiment.
The aqueous RDX solution was treated with $4.20 \mathrm{mM} \mathrm{MnO}_{4}^{-}$. Aqueous RDX solutions without $\mathrm{MnO}_{4}^{-}(n=3)$ were used as controls and monitored at each temperature. Samples were periodically collected and quenched with $\mathrm{MnCO}_{3}$ as described and analyzed for RDX by HPLC.

4-NDAB Experiments. To determine the stability of 4-NDAB in the presence of $\mathrm{MnO}_{4}^{-}$, we conducted batch experiments with 4-NDAB as the starting substrate. Batch experiments were performed in a $250-\mathrm{mL}$ Erlenmeyer flask containing $100 \mathrm{~mL}$ of $4-\mathrm{NDAB}(0.04 \mathrm{mM})$ covered with parafilm and agitated with an orbital shaker at ambient temperature $\left(24^{\circ} \mathrm{C}\right)$. $4-\mathrm{NDAB}$ was treated with $4.20,8.40,16.81$, and $33.61 \mathrm{mM}$ of $\mathrm{MnO}_{4}^{-}$. Samples were collected every $30 \mathrm{~min}$ and quenched with $\mathrm{MnCO}_{3}$ as previously described. 4-NDAB was immediately analyzed by HPLC.

RDX Nitrogen Mass Balance Experiment. Aqueous RDX $(0.10 \mathrm{mM})$ prepared from purified RDX was placed into a $10-\mathrm{mL}$ serum vial (Wheaton, Millville, NJ). The vial was closed with a silicone septum with zero headspace and crimped with an aluminum cap. So that we could precisely calculate the nitrogen mass balance, each vial was weighed before and after introducing any chemicals. Once the vial was sealed, a $21 \mathrm{G}$ (i.e., needle guage no. 21) needle and a 3-mL syringe were inserted through the septum. Helium gas was then added to the $21 \mathrm{G}$ needle to push out $2.5 \mathrm{~mL}$ of solution into the $3-\mathrm{mL}$ syringe. The $21 \mathrm{G}$ needle was removed and another syringe was inserted into the He headspace where $\mathrm{MnO}_{4}^{-}$stock solution was introduced to produce an initial concentration of $33.61 \mathrm{mM}$. Because the added $\mathrm{MnO}_{4}^{-}$stock replaced a portion of the He headspace gas back into the 3-mL syringe, experimental treatments began at ambient pressure $(t=0 \mathrm{~d})$. Vials were again weighed to determine the precise volume of solution and headspace in each replicate. To avoid possible gas losses through the needled-pierced septa, the septa were sealed with thermoplastic adhesive. Each vial was then covered with aluminum foil to prevent $\mathrm{MnO}_{4}{ }^{-}$photodegradation $(14,15)$ before shaking on a reciprocal shaker until analysis.

Sacrificial sampling occurred at 0, 1, 2, 3, 6, 9, 15, 19, 23, and $28 \mathrm{~d}$. Each replicate $(n=4)$ was used to analyze three different types of analytes. For $\mathrm{N}_{2} \mathrm{O}$ gas production, $0.5 \mathrm{~mL}$ of headspace gas was removed and injected directly into GC/ECD. For changes in solution concentrations of RDX and $\mathrm{NO}_{3}{ }^{-} /$ $\mathrm{NO}_{2}{ }^{-}, 2.0 \mathrm{~mL}$ of sample were quenched with $\mathrm{MnCO}_{3}$. One aliquot $(1.0 \mathrm{~mL})$ was analyzed by HPLC while the other was used to quantify $\mathrm{NO}_{3}^{-} / \mathrm{NO}_{2}^{-}$by IC. Each replicate solution was also analyzed for $\mathrm{MnO}_{4}{ }^{-}$with a UV spectrophotometer to ensure uniformity in $\mathrm{MnO}_{4}{ }^{-}$concentrations among replicates.

\section{Results and Discussion}

RDX Kinetics Experiments. Treating aqueous RDX with varied $\mathrm{MnO}_{4}{ }^{-}$concentrations resulted in a wide range of RDX destruction rates (i.e., pseudo-first-order rate, $k_{\text {obs }}=$ 0.02-0.37 $\mathrm{d}^{-1}$, Figure S11A). By plotting $\log \left[k_{\text {obs }}\right]$ versus $\log$ $\left[\mathrm{MnO}_{4}^{-}\right]_{\mathrm{O}}$ (Figure $\left.1 \mathrm{~A}\right)$, the calculated slope $(\beta)$ of this regression was $0.98 \pm 0.06\left(r^{2}=0.99\right)$ and indicates that reaction was first-order with respect to $\mathrm{MnO}_{4}^{-}$. Likewise, kinetic experiments estimated the reaction order with respect to RDX ( $\alpha$ ). Upon treatment of varying RDX concentrations with 33.61 $m \mathrm{M} \mathrm{MnO}_{4}^{-}$, the initial reaction rates $\left(r_{0}\right.$; based on Equation S8) were approximated from the tangent of the concentrationtime curves (Figure S12). The log of the initial reaction rate $\left(\log \left[r_{0}\right]\right)$ was plotted against initial RDX concentration to es- 

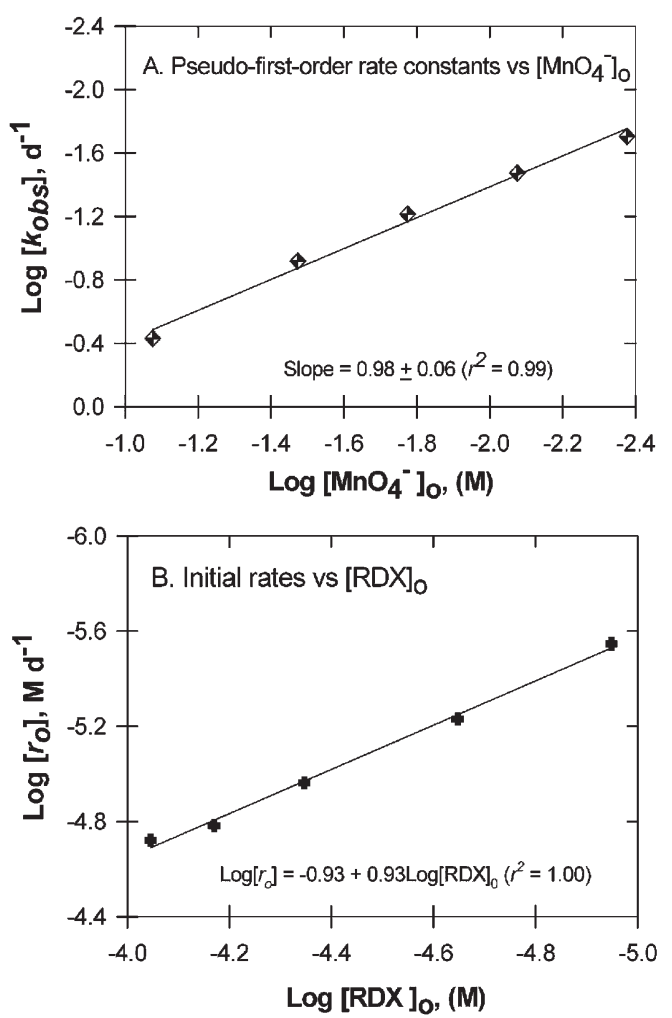

Figure 1. (A) Plot of pseudo-first-order rate constants for RDX degradation vs $\left[\mathrm{MnO}_{4}^{-}\right]_{\mathrm{O}}$. Aqueous $\mathrm{RDX}(0.09 \mathrm{mM})$ was treated with $\mathrm{MnO}_{4}{ }^{-}$ranging from 4.20 to $84.03 \mathrm{mM}$. (B) Plot of initial rates of RDX degradation vs [RDX] $]_{0}$ ranging from 0.01 to $0.09 \mathrm{mM}$ when treated with $33.61 \mathrm{mM} \mathrm{MnO}_{4}^{-}$.

timate reaction order for RDX (a). Results indicated a values very close to 1 , also verifying the reaction is first-order with respect to RDX (Figure 1B).

Both sets of kinetic experiments (Figure 1) demonstrate that the initial reaction between $\mathrm{RDX}$ and $\mathrm{MnO}_{4}^{-}$is second-order (i.e., $\alpha=\beta=1$ ) with a rate constant $\left(k^{\prime \prime}\right)$ of $4.16 \times 10^{-5} \mathrm{M}^{-1} \mathrm{~s}^{-1}$ $\left( \pm 0.22 \times 10^{-5}\right)$ (Equation S6). A compilation of destruction rates of various contaminants by $\mathrm{MnO}_{4}^{-}(4)$ revealed that a number of contaminants may react with $\mathrm{MnO}_{4}{ }^{-}$as fast as or faster than the chlorinated ethenes, the groundwater contaminants most commonly treated by $\mathrm{MnO}_{4}^{-}$. One of those contaminants reported to have a second-order rate constant similar to that of the chlorinated ethenes was TNT.(4) Given that TNT and RDX are often cocontaminants in the field, a parallel set of kinetic experiments were performed with TNT (see Supporting Information, Figures S11B and S13). These experiments concluded that the $\mathrm{TNT}-\mathrm{MnO}_{4}^{-}$reaction is first-order with respect to TNT and $\mathrm{MnO}_{4}^{-}$or second-order overall (Figure S14) with a $k^{\prime \prime}$ of $1.18 \times 10^{-3} \mathrm{M}^{-1} \mathrm{~s}^{-1}\left( \pm 0.02 \times 10^{-3}\right)$. While the second-order rate constant observed for RDX in this study is similar to those reported, $(2,4)$ our $k^{\prime \prime}$ for TNT is lower than that reported by Waldemer and Tratnyek $\left(0.03 \mathrm{M}^{-1} \mathrm{~s}^{-1}(4)\right)$ but still 28 -fold higher than what we observed for RDX, indicating a large difference in reactivity between these two explosives. This observation is perhaps not surprising and undoubtedly related to differences in chemical classes (nitramine vs nitroaromatic).

Effect of Temperature on $\mathrm{RDX}-\mathrm{MnO}_{4}{ }^{-} \mathrm{Reac}-$ tion. Albano et al.(3) previously reported that RDX transformation rates were slowed 3 -fold under temperatures indicative of aquifer conditions $\left(11.5\right.$ vs $\left.23^{\circ} \mathrm{C}\right)$. We treated aqueous
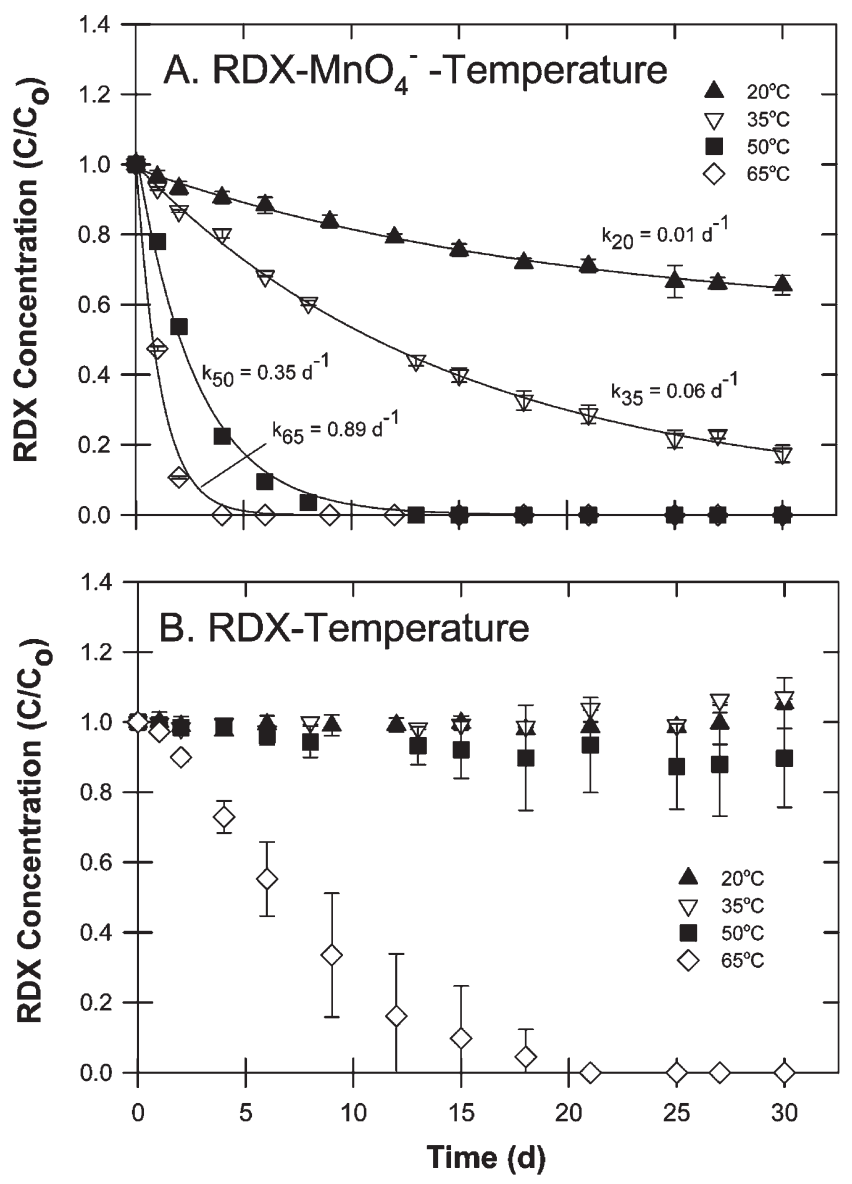

Figure 2. Temporal changes in RDX concentration in aqueous solution treated with $4.20 \mathrm{mM}$ of $\mathrm{MnO}_{4}{ }^{-}$at $20,35,50$, or $65^{\circ} \mathrm{C}$. Bars indicate sample standard deviations $(n=3)$.

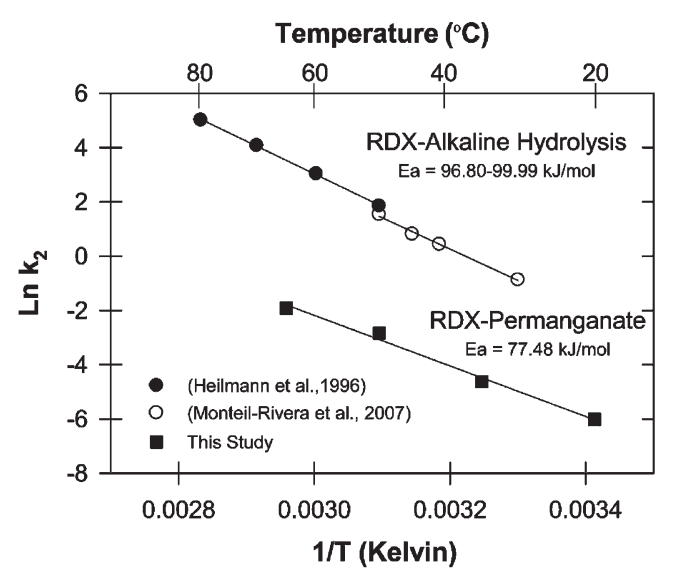

Figure 3. Arrhenius plot of second-order rate constants.

RDX with $\mathrm{MnO}_{4}^{-}$at four temperatures to further elucidate the temperature dependency of the reaction at elevated temperatures. Results showed the RDX destruction rates were significantly increased with increasing temperature with pseudofirst-order rates ranging from 0.01 to $0.89 \mathrm{~d}^{-1}$ (Figure 2A). At $20{ }^{\circ} \mathrm{C}$, RDX concentration was only reduced by $30 \%$ after $30 \mathrm{~d}$ $\left(k=0.01 \mathrm{~d}^{-1}\right)$ while complete RDX transformation $(100 \%)$ was achieved within $6 \mathrm{~d}$ at $65{ }^{\circ} \mathrm{C}\left(k=0.89 \mathrm{~d}^{-1}\right)$. A comparison of 


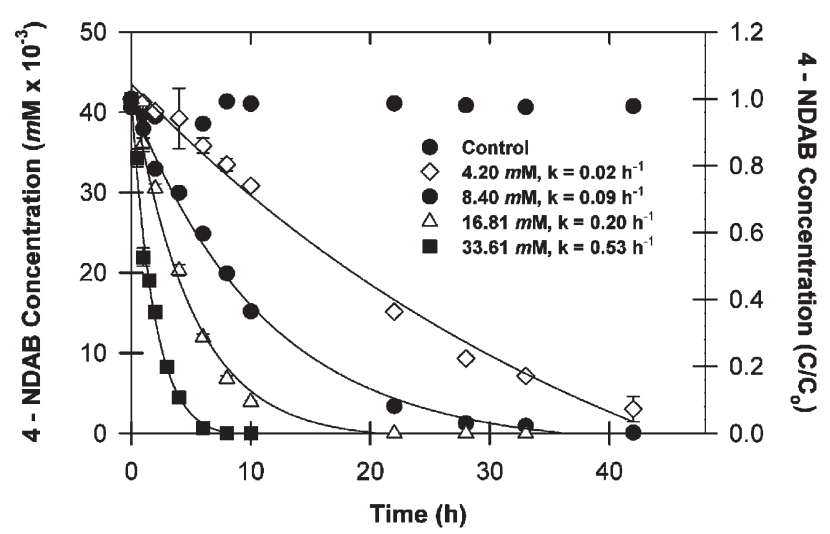

Figure 4. Loss of 4-NDAB concentration following treatment of 4-NDAB aqueous solution with various concentrations of $\mathrm{MnO}_{4}^{-}$ and quenching with $0.10 \mathrm{~g} \mathrm{MnCO}_{3}$ (per $\mathrm{mL}$ ). Bars indicate sample standard deviations $(n=3)$.

controls (temperature only) showed that RDX was relatively stable at temperatures $\leq 50^{\circ} \mathrm{C}$ but decreases in RDX concentrations were observed at $65^{\circ} \mathrm{C}$, albeit at a slower rate than when $\mathrm{MnO}_{4}^{-}$was also present (Figure 2B). A comparison of previously reported destruction rates shows that, in order to get the destruction rate we observed at $65^{\circ} \mathrm{C}$ with $4.20 \mathrm{mM} \mathrm{MnO}{ }_{4}^{-}$, Adam et al.(2) needed $168 \mathrm{mM} \mathrm{MnO}_{4}{ }^{-}$at room temperature (a 40-fold higher concentration).

Computed pseudo-first-order constants $\left(k_{\text {obs }}\right.$, Figure 2A) were converted to second-order rate constants at $\beta=1$ based on Equation S6 (see Supporting Information, SI-6, SI-7, and Table S2). The temperature dependency was further calculated by using an Arrhenius plot (Figure 3). The activation energy for the reaction between RDX and $\mathrm{MnO}_{4}{ }^{-}$in the temperature range $20-65{ }^{\circ} \mathrm{C}$ was $77.48 \pm 5.13 \mathrm{~kJ} / \mathrm{mol}$ (Figure 3) with an Arrhenius parameter (i.e., $\ln A$ ) of $25.77 \pm 1.96 \mathrm{~L} / \mathrm{mol} \mathrm{min}$. For comparison, the temperature dependency of RDX hydrolysis from previously published work is also plotted (Figure 3). Results show that the $\mathrm{RDX}-\mathrm{MnO}_{4}{ }^{-}$reaction is less temperature sensitive than alkaline hydrolysis and second-order rate constants for $\mathrm{RDX}-\mathrm{MnO}_{4}^{-}$are considerably lower than the rate constants for alkaline hydrolysis observed under similar temperatures.

4-NDAB Experiments. Past research has shown that $4-\mathrm{NDAB}$ is an RDX degradation product after ring cleavage for both abiotic and biological treatments, $(8,9,16)$ such as aerobic biodegradation(16-19) and alkaline hydrolysis.(6) In aerobic degradation, $1 \mathrm{~mol}$ of RDX yields $1 \mathrm{~mol}$ of 4-NDAB and 2 mols of $\mathrm{NO}_{2}{ }^{-}$.(20) Adam et al. $(2,21)$ also separately reported observing 4-NDAB during treatment with $\mathrm{MnO}_{4}^{-}$or ozone. While Adam et al.(2) also used peroxide to quench $\mathrm{MnO}_{4}^{-}$, which would explain the detection of NDAB (Figure S6B), their experiments with ozone required no quenching agent. (21) A question surrounding 4-NDAB detection during RDX degradation is whether it is formed during the $\mathrm{RDX}-\mathrm{MnO}_{4}{ }^{-}$ reaction or if it is just a product of the quenching process (see Supporting Information, SI-4).

Because only a trace of 4-NDAB (Figure S6) was observed in the $\mathrm{RDX}-\mathrm{MnO}_{4}^{-}$reaction when $\mathrm{MnCO}_{3}$ was used as a quenching agent, additional explanations for its lack of detection were pursued. In testing the stability of 4-NDAB under the different $\mathrm{pH}$ values, we found that 4 -NDAB was relatively stable for the first $10 \mathrm{~d}$ ( $>90 \%$ remaining) (Figure S8). Therefore, the stability of NDAB was not influenced by the $\mathrm{pH}$ of our treatments.

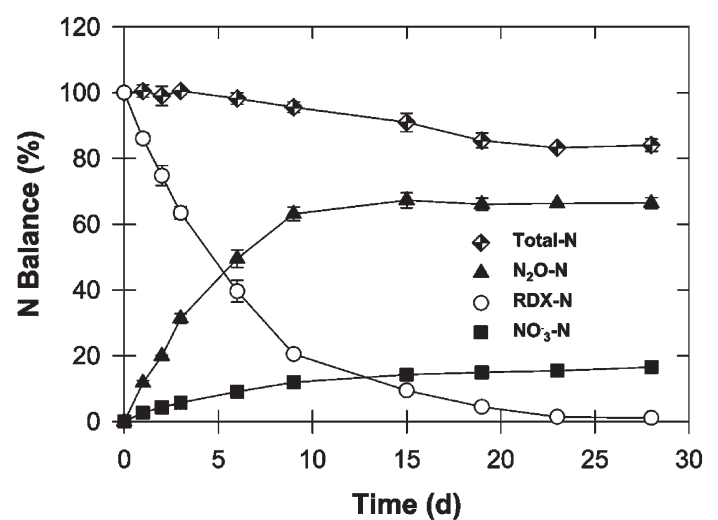

Figure 5. Nitrogen mass balance results from tracking loss of RDX and production of $\mathrm{N}_{2} \mathrm{O}$ and $\mathrm{NO}_{3}{ }^{-}$. Bars indicate sample standard deviations $(n=4)$.

We also used 4-NDAB as the starting substrate by treating it with varying concentrations of $\mathrm{MnO}_{4}^{-}$. Results showed that $4-\mathrm{NDAB}$ is much more quickly transformed by $\mathrm{MnO}_{4}^{-}$ than RDX, with transformation occurring within hours (Figure 4) versus days for RDX (Figure S6A). 4-NDAB is likely oxidized faster than RDX because oxidation of the formamide group to a carbamic acid and the subsequent decarboxylation are known to be very fast reactions.(22-24) While 4-NDAB was found to be a dead-end product of RDX via photodenitration,(8) aerobic biodegradation,(5) and alkaline hydrolysis,(6) we showed that it was not stable in $\mathrm{MnO}_{4}^{-}$(Figure 4). Treatment of 4-NDAB with $\mathrm{MnO}_{4}^{-}$also produced $\mathrm{N}_{2} \mathrm{O}$. A separate $\mathrm{N}$-mass balance attempt showed that $>50 \%$ of the $\mathrm{N}$ in $4-\mathrm{NDAB}$ was converted to $\mathrm{N}_{2} \mathrm{O}$. In contrast to what was observed with RDX (see below), $\mathrm{NO}_{3}^{-}$was not formed in the 4-NDAB- $\mathrm{MnO}_{4}^{-}$reaction.

Nitrogen Mass Balance Experiment. Using purified RDX, we prepared an aqueous solution and treated it with $\mathrm{MnO}_{4}^{-}$. Initial experiments screened for a variety of $\mathrm{N}$ containing products $\left(\mathrm{NO}_{2}^{-}, \mathrm{NO}_{3}^{-}, \mathrm{N}_{2} \mathrm{O}, \mathrm{NH}_{4}^{+}, 4-\mathrm{NDAB}\right.$, and MEDINA), but only $\mathrm{NO}_{3}{ }^{-}$and $\mathrm{N}_{2} \mathrm{O}$ were found to be formed in significant quantities. Temporal tracking of RDX, $\mathrm{N}_{2} \mathrm{O}$, and $\mathrm{NO}_{3}{ }^{-}$revealed that, after approximately $25 \%$ of the RDX had been transformed, a 99\% N balance was obtained (day 2, Figure 5). By day 9, roughly $80 \%$ of the RDX had been transformed and RDX, $\mathrm{N}_{2} \mathrm{O}$, and $\mathrm{NO}_{3}{ }^{-}$still constituted $95.6 \%$ of the $\mathrm{N}$ balance. During the time when most of the RDX was transformed (i.e., 0-9 d), roughly 5 times as much $\mathrm{N}_{2} \mathrm{O}$ was produced than $\mathrm{NO}_{3}^{-}$(molar basis). The production of $\mathrm{N}_{2} \mathrm{O}$ declined after $9 \mathrm{~d}$, and concentrations reached a plateau by day 15; $\mathrm{NO}_{3}^{-}$production continued with a slow steady increase until $28 \mathrm{~d}$, the time when RDX was no longer detectable (Figure 5). The nitrous oxide production was calculated by summing the direct headspace measurement plus the calculated dissolved liquid phase concentration in equilibrium with the measured gas phase concentration.(25) Possible reasons why $\mathrm{N}_{2} \mathrm{O}$ production did not continue to mirror RDX loss after $15 \mathrm{~d}$ include the inability of our microcosms to retain the headspace gases, the relationship between dissolved (i.e., calculated) and headspace $\mathrm{N}_{2} \mathrm{O}$ concentrations changing as headspace pressure (i.e., $\mathrm{N}_{2} \mathrm{O}$ production) increased, or other nitrogen gases or dissolved species being produced.

The possibility of other $\mathrm{N}$-containing gases $\left(\mathrm{NO}, \mathrm{NO}_{2}, \mathrm{~N}_{2}\right)$ forming from the $\mathrm{RDX}-\mathrm{MnO}_{4}{ }^{-}$reaction was investigated using ${ }^{15} \mathrm{~N}-\mathrm{RDX}$ but could not be confirmed [see Supporting In- 


\section{Oxidation of methylene by hydride abstraction, cation hydrolysis}

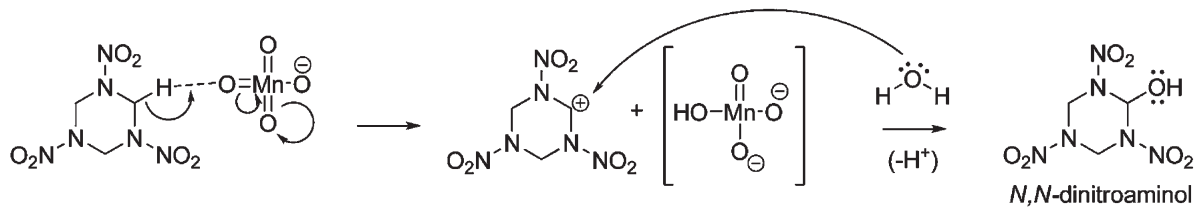

Oxidation of $\mathrm{N}, \mathrm{N}$-dinitroaminol to $\mathrm{N}, \mathrm{N}$-dinitroimide by permanganate<smiles>O=[N+]([O-])C1C(O)N([N+](=O)[O-])CN([N+](=O)[O-])N1[N+](=O)[O-]</smiles>

Imide hydrolysis and decarboxylation

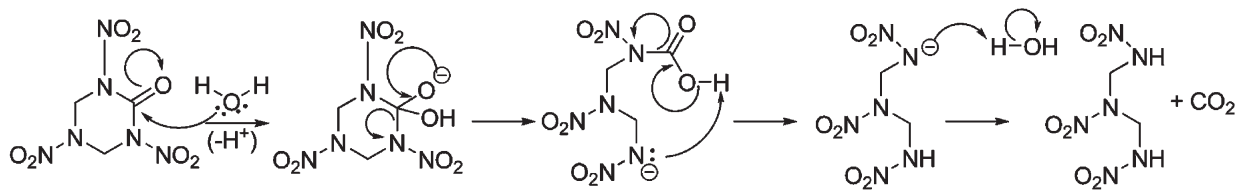

\section{Overall reaction mechanism}

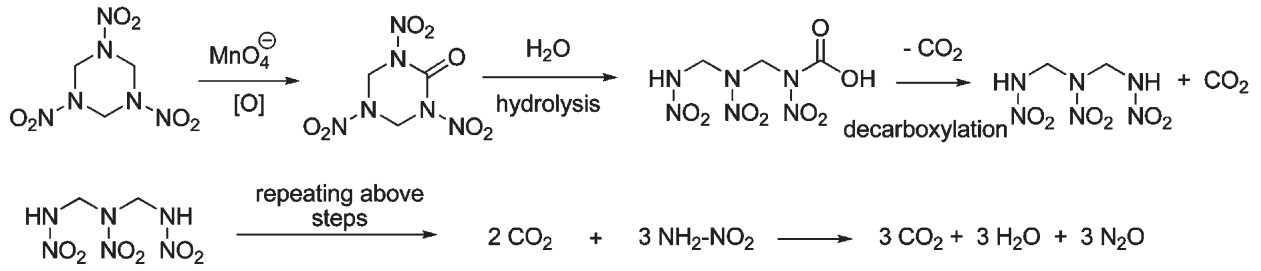

\section{Generation of $\mathrm{NO}_{3}{ }^{-}$and trace of 4-NDAB: Possible examples}

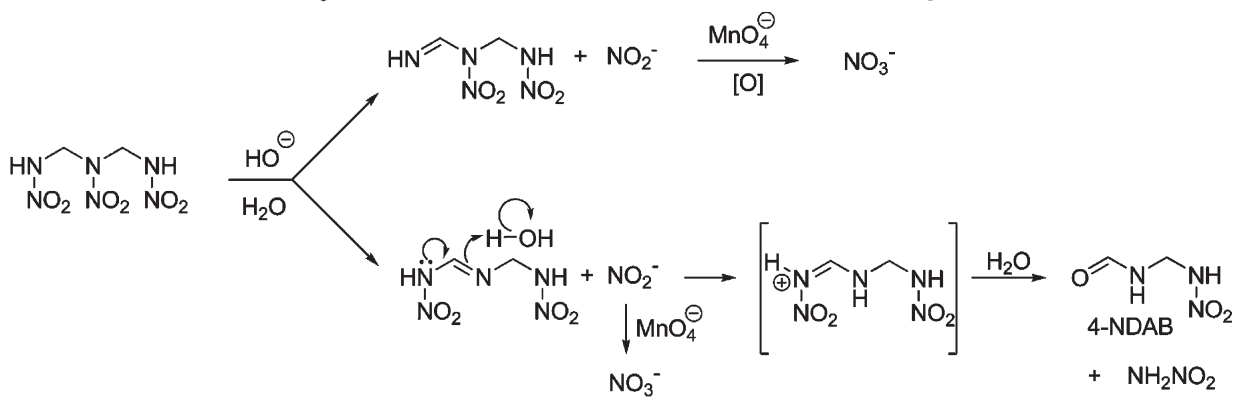

Figure 6. Proposed RDX degradation pathway of $\mathrm{RDX}-\mathrm{MnO}_{4}{ }^{-}$reaction under neutral $\mathrm{pH}$.

formation, SI-1(analysis of N-containing gas)]. Previous attempts to obtain a nitrogen balance during treatment of RDX have had mixed results. When $4-\mathrm{NDAB}$ is a significant product, good N-balances have been obtained. For instance, Balakrishnan et al.(6) studied alkaline hydrolysis of RDX ( $\mathrm{pH}$ 10-12.3) and found $90.7 \%$ of nitrogen mass balance [i.e., $\mathrm{NO}_{2}^{-}(16.2 \%), \mathrm{N}_{2} \mathrm{O}(25.6 \%), \mathrm{NH}_{3} / \mathrm{NH}_{4}^{+}(1.3 \%)$, and 4-NDAB $(47.6 \%)]$. When reductive treatments to RDX have been imposed, N-balances have generally been low (e.g., References 26 and 27).

RDX Degradation Mechanism. RDX is known to be degraded within days ( $\sim 15 \mathrm{~d}$ ) by base hydrolysis ( $\mathrm{pH} 10)$ at ambient temperature(6) and within hours to minutes at elevated temperatures. $(28,29)$ We show that RDX was degraded by $\mathrm{MnO}_{4}^{-}$at neutral $\mathrm{pH}$ over several days at room temperature (Figure S6A) and that increasing temperature increased destruction rates (Figures 2 and 3). On the basis of results obtained from the various experiments (quenching agents, $\mathrm{pH}$, temperatures, and activation energies), and the lack of readily identifiable carbon-containing intermediates (other than a trace of $4-\mathrm{NDAB}$ ), the initial step in the $\mathrm{RDX}-\mathrm{MnO}_{4}{ }^{-}$reaction is likely rate-limiting. On the basis of the various experimental treatments imposed, we believe this initial step can be described in one of two ways. When solution $\mathrm{pH}$ was alkaline, either as an artifact of the quenching agent (Figure S6B) or purposely increased (Figure S6C), then it is probable that the first step in the $\mathrm{RDX}-\mathrm{MnO}_{4}{ }^{-}$reaction is similar to the previously reported hydrolysis pathway (N-denitration;(6) see Supporting Information, SI-9, Figure S18). This mechanism would produce $4-\mathrm{NDAB}$, which was observed. And although $4-\mathrm{NDAB}$ is a relatively stable intermediate during alkaline hydrolysis,(28) we show that 4-NDAB reacts with $\mathrm{MnO}_{4}{ }^{-}$at a much faster rate than RDX (Figures 2, 4, and S6A). Under alkaline $\mathrm{pH}$ then, 4-NDAB was apparently produced by hydrolysis faster than it is oxidized by $\mathrm{MnO}_{4}^{-}$(Figures S6B and S6C), which allowed it to be detected. 
Under neutral $\mathrm{pH}$, which is more indicative of treating aqueous RDX with $\mathrm{MnO}_{4}{ }^{-}$( $\mathrm{pH} 7.2$ observed), we believe the initial step is an oxidation mechanism that begins with abstraction of a hydride from the methylene carbon by $\mathrm{MnO}_{4}^{-}$ causing a carbocation to form (Figure 6). This proposed step is supported by past research on $\mathrm{MnO}_{4}^{-}$-amine reactions.(30-32) Permanganate oxidation of amines has been shown to proceed in one of two ways, namely single electron transfer (SET) from the amine nitrogen and hydride or hydrogen atom abstraction from the carbon. A detailed consideration of both possible first steps (SET vs hydride loss) for RDX oxidation is presented in Supporting Information (SI-8, Figure S17). In brief, theoretical explanations and experimental observations indicate that SET will dominate the reactivities of tertiary amines with $\mathrm{MnO}_{4}{ }^{-}$ but hydrogen abstraction becomes more prominent in secondary and primary amines. $(31,32)$ Second-order rate constants have also been shown to significantly decrease when the mechanism shifts from SET to hydrogen atom loss.(31) Moreover, when the initial intermediate can be stabilized with resonance as previously shown for benzylamine, the rate determining step proceeds by loss of hydride (or hydrogen atom) rather than SET.(30) Given that the initial carbocation intermediate proposed for RDX (Figure 6) would be more stable than the intermediate formed by SET (Figure S17), we believe the hydride loss mechanism would be operative.

Following through with the proposed mechanism (Figure 6), the carbocation intermediate would react with water by hydrolysis to form a C-O bond (alcohol) and the resulting $\mathrm{N}, \mathrm{N}-$ dinitroaminol with $\mathrm{MnO}_{4}{ }^{-}$itself to form an imide. It is well established that $\mathrm{MnO}_{4}^{-}$oxidizes alcohols to carbonyl compounds,(33) but the mechanisms have been shown to change completely as $\mathrm{pH}$, reagent, and structure are varied.(34-37) To our knowledge an oxidation mechanism for the proposed $\mathrm{N}, \mathrm{N}$-dinitroaminol has not been studied, so no specific mechanism for this conversion (aminol to imide) is presented. Once formed, however, water would attack the imide carbon (hydrolysis) to open the ring and lead to a carbamic acid/amide anion. The carbamic acid/amide ion would then undergo decarboxylation and liberation of $\mathrm{CO}_{2}$. The accelerated rate of $\mathrm{N}, \mathrm{N}$-dinitroimide hydrolysis and decarboxylation has been previously observed in $\mathrm{N}$-nitrourea chemistry.(38-40) This same three-step cycle of oxidation, hydrolysis, and decarboxylation would continue leading to the production of $\mathrm{CO}_{2}$ and $\mathrm{H}_{2} \mathrm{NNO}_{2}$ (nitramide), which would rapidly be converted to $\mathrm{N}_{2} \mathrm{O}(6)$ and water (Figure 6).

While the proposed mechanisms are presented separately (Figures 6 and S18) and in a stepwise fashion, it is possible that several of these steps occur simultaneously. The dominant mechanism, however, can be inferred by the distribution of nitrogen-containing degradation products observed. RDX hydrolysis is reported to produce $\mathrm{N}_{2} \mathrm{O}, \mathrm{NO}_{2}{ }^{-}, \mathrm{NH}_{3}$, and $\mathrm{N}_{2}$ in the proportions 3.2:4.7:2.6:1, respectively.(28) The hydride removal mechanism predicts that if RDX is exclusively degraded by oxidation, only $\mathrm{N}_{2} \mathrm{O}$ would be produced; any nitrate observed would have to result from hydrolysis of postoxidation intermediates (Figure 6). Restated, if the solution chemistry is dominated by oxidation, we should observe ratios of $\mathrm{N}_{2} \mathrm{O}$ / $\mathrm{NO}_{3}{ }^{-}$which strongly favor $\mathrm{N}_{2} \mathrm{O}$. If the process is mainly hydrolysis followed by oxidation, the same ratio would strongly favor $\mathrm{NO}_{3}^{-}$. Our experiments indicate that $\mathrm{RDX}-\mathrm{MnO}_{4}{ }^{-}$reaction produces $\mathrm{N}_{2} \mathrm{O}$ and $\mathrm{NO}_{3}{ }^{-}$in a molar ratio of about 5:1, leading us to conclude that oxidation processes are dominant under the conditions we report.
Supporting Information, providing details of experimental procedures and further explanation of results, is presented following the References.

Acknowledgment - Funding was provided in part by the EPA Region 7 and the Environmental Security Technology Certification Program (ESTCP), Project ER-0635. Partial support was also provided by the University of Nebraska School of Natural Resources and Water Center. This paper is a contribution of Agricultural Research Division Projects NEB-38-071. The authors also gratefully acknowledge Ms. Melissa S. Love and Dr. Daniel M. Steffenson (Chemistry Department, Albion College, Albion, MI), for their suggestions and contribution to this study.

\section{References}

1. Oberle, D. W.; Schroder, D. L.Design considerations for in-situ chemical oxidation. In Chemical Oxidation and Reactive Barriers: Remediation of Chlorinated and Recalcitrant Compounds; Wickramanayake, G. B., Gavaskar, A. R.,Chen,, A. S. C., Eds.; Battelle Press: Columbus, OH, 2000; pp 91-99.

2. Adam, M. L.; Comfort, S. D.; Snow, D. D.Remediating RDX-contaminated ground water with permanganate: Laboratory investigations for the Pantex perched aquifer J. Environ. Qual. 2004, 33 ( 6) 2165- 2173

3. Albano, J. A.; Comfort, S. D.; Zlotnik, V.; Halihan, T.; Burbach, M.; Chokejaroenrat, C.; Onanong, S.; Clayton, W.In situ chemical oxidation of RDX-contaminated ground water with permanganate at the Nebraska Ordnance Plant Ground Water Monit. Rem. 2010, 30 ( 3) 96- 106

4. Waldemer, R. H.; Tratnyek, P. G.Kinetics of contaminant degradation by permanganate Environ. Sci. Technol. 2006, 40 (3) 1055- 1061

5. Fournier, D.; Halasz, A.; Spain, J.; Fiurasek, P.; Hawari, J.Determination of key metabolites during biodegradation of hexahydro-1,3,5-trinitro-1,3,5-triazine with Rhodococcus sp strain DN22 Appl. Environ. Microbiol. 2002, 68 (1) 166- 172

6. Balakrishnan, V. K.; Halasz, A.; Hawari, J.Alkaline hydrolysis of the cyclic nitramine explosives RDX, HMX, and CL-20: New insights into the degradation pathways obtained by the observation of novel intermediates Environ. Sci. Technol. 2003, 37 ( 9) $1838-1843$

7. Halasz, A.; Groom, C.; Zhou, E.; Paquet, L.; Beaulieu, C.; Deschamps, S.; Corriveau, A.; Thiboutot, S.; Ampleman, G.; Dubois, C.; Hawari, J.Detection of explosives and their degradation products in soil environments J. Chromatogr., A 2002, 963 (1-2) $411-418$

8. Hawari, J.; Halasz, A.; Groom, C.; Deschamps, S.; Paquet, L.; Beaulieu, C.; Corriveau, A.Photodegradation of RDX in aqueous solution: A mechanistic probe for biodegradation with Rhodococcus sp Environ. Sci. Technol. 2002, 36 ( 23) 5117- 5123

9. Hawari, J.Biodegradation of RDX and HMX: From basic research to field application. In Biodegradation of Nitroaromatic Compounds and Explosives; Spain, J. C.; Hughes, J. B.; Knackmuss, H. J., Eds.; CRC Press: Boca Raton, FL, 2000; pp 277- 310.

10. McCormick, N. G.; Cornell, J. H.; Kaplan, A. M. The Anaerobic Biotransformation of RDX, HMX, and Their Acetylated Derivatives; NATICK/TR-85/007; U.S. Army Natick Research and Development Center: Natick, MA, 1984

11. McCormick, N. G.; Cornell, J. H.; Kaplan, A. M.Biodegradation of hexahydro-1,3,5-trinitro-1,3,5-triazine Appl. Environ. Microbiol. 1981, 42 ( 5) 817- 823

12. Hoffsommer, J. C.; Kubose, D. A.; Glover, D. J.Kinetic isotope effects and intermediate formation for the aqueous alkaline homogenous hydrolysis of 1,3,5-triaza-1,3,5-trinitrocyclohexane (RDX) J. Phys. Chem. 1977, 81 ( 5) 380- 385 
13. Casado, J.; Lopez-Quintela, M. A.; Lorenzo-Barral, F. M.The initial rate method in chemical kinetics: Evaluation and experimental illustration J. Chem. Educ. 1986, 63 (5) 450- 452

14. Mathews, J. H.; Dewey, L. H.A quantitative study of some photochemical effects produced by ultra-violet light J. Phys. Chem. 1913, 17 ( 3) 211- 218

15. Zimmerman, G.Photochemical decomposition of aqueous permanganate ion J. Chem. Phys. 1955, 23 ( 5) 825- 832

16. Fournier, D.; Trott, S.; Hawari, J.; Spain, J.Metabolism of the aliphatic nitramine 4-nitro-2,4-diazabutanal by Methylobacterium sp strain JS178 Appl. Environ. Microbiol. 2005, 71 ( 8) 4199- 4202

17. Bernstein, A.; Ronen, Z.; Adar, E.; Nativ, R.; Lowag, H.; Stichler, W.; Meckenstock, R. U.Compound-specific isotope analysis of RDX and stable isotope fractionation during aerobic and anaerobic biodegradation Environ. Sci. Technol. 2008, 42 ( 21) 7772- 7777

18. Fournier, D.; Halasz, A.; Spain, J.; Spanggord, R. J.; Bottaro, J. C.; Hawari, J.Biodegradation of the hexahydro-1,3,5-trinitro-1,3,5-triazine ring cleavage product 4-nitro-2,4-diazabutanal by Phanerochaete chrysospotium Appl. Environ. Microbiol. 2004, 70 ( 2) 1123- 1128

19. Bhushan, B.; Trott, S.; Spain, J. C.; Halasz, A.; Paquet, L.; Hawari, J.Biotransformation of hexahydro-1,3,5-trinitro-1,3,5-triazine RDX by a rabbit liver cytochrome p450: Insight into the mechanism of RDX biodegradation by Rhodococcus sp strain DN22 Appl. Environ. Microbiol. 2003, 69 ( 3) 1347- 1351

20. Jackson, R. G.; Rylott, E. L.; Fournier, D.; Hawari, J.; Bruce, N. C.Exploring the biochemical properties and remediation applications of the unusual explosive-degrading P450 system XplA/B Proc. Natl. Acad. Sci. U.S.A. 2007, 104 ( 43) $16822-16827$

21. Adam, M. L.; Comfort, S. D.; Snow, D. D.; Cassada, D.; Morley, M. C.; Clayton, W.Evaluating ozone as a remedial treatment for removing RDX from unsaturated soils J. Environ. Eng. 2006, 132 (12) 1580- 1588

22. Joh, T. H.; Ross, R. A.; Reis, D. J.A simple and sensitive assay for dopamine- $\beta$-hydroxylase Anal. Biochem. 1974, 62 ( 1) 248- 254

23. Pal, B. C.; Doherty, D. G.; David, G.Explosive mixtures Chem. Eng. News 1981, 59 ( 17) 47

24. Fadda, F.; Argiolas, A.; Melis, M. R.; Montis, G. D.; Gessa, G. L.Suppression of voluntary ethanol consumption in rats by gamma-butyrolactone Life Sci. 1983, 32 ( 13) 1471- 1477

25. Hudson, F.Standard operating procedure: Sample preparation and calculations for dissolved gas analysis in water samples using a GC headspace equilibration technique; U.S. EPA: Washington, DC, 2004; http://www.epa.gov./ne/info/testmethods/pdfs/RSKsop175v2.pdf (accessed February 25, 2009).

26. Zhao, J. S.; Paquet, L.; Halasz, A.; Hawari, J.Metabolism of hexahydro-1,3,5-trinitro-1,3,5-triazine through initial reduction to hexahydro-1-nitroso-3,5-dinitro-1,3,5-triazine followed by denitration in Clostridium bifermentans HAW-1 Appl. Microbiol. Biotechnol. 2003, 63 ( 2) 187- 193

27. Gregory, K. B.; Larese-Casanova, P.; Parkin, G. F.; Scherer, M. M.Abiotic transformation of hexahydro-1,3,5-trinitro-1,3,5-triazine by FeII bound to magnetite Environ. Sci. Technol. 2004, 38 ( 5) 1408- 1414

28. Heilmann, H. M.; Wiesmann, U.; Stenstrom, M. K.Kinetics of the alkaline hydrolysis of high explosives RDX and HMX in aqueous solution and adsorbed to activated carbon Environ. Sci. Technol. 1996, 30 ( 5) 1485- 1492

29. Monteil-Rivera, F.; Paquet, L.; Giroux, R.; Hawari, J.Contribution of hydrolysis in the abiotic attenuation of RDX and HMX in coastal waters J. Environ. Qual. 2008, 37 ( 3) $858-864$

30. Wei, M. M.; Stewart, R.The mechanisms of permanganate oxidation. VIII. Substituted benzylamines J. Am. Chem. Soc. 1966, 88 ( 9) 1974- 1979

31. Rosenblatt, D. H.; Davis, G. T.; Hull, L. A.; Forberg, G. D.Oxidations of amines. V. Duality of mechanism in the reactions of aliphatic amines with permanganate J. Org. Chem. 1968, 33 ( 4) 1649- 1650

32. Mata-Perez, F.; Perez-Benito, J. F.Kinetics and mechanisms of oxidation of methylamine by permanganate ion Can. J. Chem. 1987, 65 ( 10) 2373- 2379

33. Rawalay, S. S.; Shechter., S.Oxidation of primary, secondary, and tertiary amines with neutral permanganate. Simple method for degrading amines to aldehydes and ketones J. Org. Chem. 1967, 32 ( 10) 3129- 3131

34. Kurz, J. L.Transition state characterization for the permanganate oxidation of fluoral hydrate J. Am. Chem. Soc. 1964, 86 ( 11) $2229-2232$

35. Lee, D. G.; Noureldin, N. A.Heterogeneous permanganate oxidations. 3. Mechanism of the oxidation of alcohols by hydrated copper permanganate J. Am. Chem. Soc. 1983, 105 (10) 3188- 3191

36. Lee, D. G.; Chen, T.The oxidation of alcohols by permanganate. A comparison with other high-valent transition-metal oxidants J. Org. Chem. 1991, 56 ( 18) 5341- 5345

37. Banerji, K. K.Kinetics and mechanism of the oxidation of aliphatic alcohols by acid permanganate Bull. Chem. Soc. Jpn. 1973,46 ( 11) 3623- 3624

38. Lobanova, A. A.; Sataev, R. R.; Popov, N. I.; II'yasov, S. G. Chemistry of urea nitro derivatives: I. Synthesis of nitramide from N,N'-dinitrourea Russ. J. Org. Chem. 2000, 36 ( 2) 164- 167

39. Lobanova, A. A.; II'yasov, S. G.; Popov, N. I.; Sataev, R. R.Chemistry of urea nitro derivatives: II. Synthesis of nitramide from $\mathrm{N}, \mathrm{N}^{\prime}$-dinitrourea. New reactions of nitramide Russ. J. Org. Chem. 2002, 38 ( 1) 1- 6

40. II'yasov, S. G.; Lobanova, A. A.Nitration of N-alkyl-N'nitroureas Russ. J. Org. Chem. 2002, 38 (12) 1806-1807 


\section{Supporting Information for:}

\section{Transformation of Hexahydro-1,3,5-trinitro-1,3,5-triazine (RDX) by Permanganate}

CHANAT CHOKEJAROENRAT ${ }^{\dagger}$, STEVE D. COMFORT ${ }^{\ddagger}, *$, CLIFFORD HARRIS ${ }^{\S}$, DANIEL D. SNOW ", DAVID CASSADA ", CHAINARONG SAKULTHAEW ‡, AND TUNLAWIT SATAPANAJARU ${ }^{\perp}$

* Corresponding author phone: 402-472-1502; fax: 402-472-7904; e-mail: scomfort@unl.edu.

${ }^{\dagger}$ Department of Civil Engineering, University of Nebraska-Lincoln

‡ School of Natural Resources, University of Nebraska-Lincoln

$\S$ Department of Chemistry, Albion College, MI

"Water Science Laboratory, University of Nebraska-Lincoln

$\perp$ Department of Environmental Science, Kasetsart University, Bangkok, Thailand

Supporting Information for Chokejaroenrat et al./ ENVIRONMENTAL SCIENCE \& TECHNOLOGY SUBMISSION 


\section{Contents}

SI-1. Additional Experimental Section

Figs. S1; S2

SI-2. RDX Purification

SI-3 Experimental Controls

Fig. S3; Table S1; Figs. S4; S5

SI-4. Effect of quenching agents on RDX degradation products

Figs. S6; S7; S8

SI-5. RDX Batch Experiments (Autocatalysis of permanganate)

Figs. S9; S10

SI-6. Kinetic Models

Figs. S11; S12; S13; S14

SI-7. Temperature dependency

Table S2

SI-8 Single electron transfer versus hydride (or hydrogen) atom removal

Fig. S15; S16; S17

SI-9. Proposed RDX degradation via proton abstraction

Fig. S18

SI-10. References 


\section{SI-1. Additional Experimental Section}

Chemical Standards. Commercial-grade RDX ( 90\% purity) was obtained from the Fort Detrick U.S. Biomedical Research and Development Laboratory (Frederick, MD). 4-nitro-2,4-diazabutanal, (4-NDAB, >99\% purity) was custom synthesized by SRI International (Menlo Park, CA). Sodium permanganate $\left(\mathrm{NaMnO}_{4}, 40 \%\right.$ by weight) and potassium permanganate $\left(\mathrm{KMnO}_{4}\right)$ were obtained from Fisher Scientific (Pittsburgh, PA). Reagent grade hydrogen peroxide $\left(\mathrm{H}_{2} \mathrm{O}_{2}, 30 \% \mathrm{v} / \mathrm{v}\right)$, methanol, manganous sulfate $\left(\mathrm{MnSO}_{4} \cdot \mathrm{H}_{2} \mathrm{O}\right)$ (J.T.Baker, Phillipsburgh, $\left.\mathrm{NJ}\right)$, and manganous carbonate $\left(\mathrm{MnCO}_{3}\right.$, 99.9\%, metals basis) (Alfa Aesar, Ward Hill, MA) were used as purchased. All solvents used in this research were HPLC grade (Fisher Scientific, Springfield, NJ). An analytical RDX standard $(100 \mu \mathrm{g} / \mathrm{mL})$ in a 50:50 acetonitrile-methanol matrix was purchased from AccuStandard (New Haven, CT). Nitrate $\left(\mathrm{NO}_{3}{ }^{-}\right)$, Ammonium $\left(\mathrm{NH}_{4}{ }^{+}\right)(1000 \mathrm{mg} / \mathrm{L}$, GFS Chemicals, Columbus, $\mathrm{OH})$ and nitrite $\left(\mathrm{NO}_{2}{ }^{-}\right)(1000 \mathrm{mg} / \mathrm{L}$, Absolute Standards Inc., Hamden, CT) standards were used as purchased. Nitrous oxide $\left(\mathrm{N}_{2} \mathrm{O}\right)$ standards were prepared from the $2 \%$ stock gases (mole basis) obtained from Scott Specialty Gases (Plumsteadville, PA).

High-Performance Liquid Chromatography (HPLC). Temporal changes in RDX and degradate concentrations were quantified at a $220 \mathrm{~nm}$ by HPLC equipped with a photodiode array detector (Shimadzu Scientific Instruments, Columbia, MD). Peak separations were performed by injecting $20 \mu \mathrm{L}$ of sample into a Supelcosil LC-8, $250 \mathrm{x}$ $4.6 \mathrm{~mm}$, (Supelco, Sigma-Aldrich Corporation, PA) or a Fluophase PFP perfluorinated column, $250 \times 4.6 \mathrm{~mm}$, coupled with a guard column (Thermo Scientific, MA). A variety of mobile phases and flow rates $(0.50-1.50 \mathrm{~mL} / \mathrm{min})$ were tested to separate peaks but the typical mobile phase was an isocratic mixture of methanol and $\mathrm{H}_{2} \mathrm{O}(30: 70)$, or acetonitrile and $\mathrm{H}_{2} \mathrm{O}(50: 50)$ at a flow rate of $0.75 \mathrm{~mL} / \mathrm{min}$. 
Ion Chromatography (IC). Analysis of $\mathrm{NO}_{2}{ }^{-} / \mathrm{NO}_{3}{ }^{-}$and $\mathrm{NH}_{4}{ }^{+}$were performed with a Dionex DX-120 Ion Chromatograph (Sunnyvale, CA) with suppressed conductivity detection (conductivity detector, CDM-3). For anion analysis, separation was performed with an AS-15 lonPac column, $250 \times 4.0 \mathrm{~mm}$, using an eluent of $38 \mathrm{mM} \mathrm{NaOH}$ at a flow rate of $1 \mathrm{~mL} / \mathrm{min}$. For cation analysis, separation was performed with a CS12A lonPac column, $250 \times 4.0 \mathrm{~mm}$, using an isocratic eluent of $5.5 \mathrm{mM} \mathrm{H}_{2} \mathrm{SO}_{4}$ at a flow rate of 1.2 $\mathrm{mL} / \mathrm{min}$. The injection volume for both analyses was $25 \mu \mathrm{L}$. To effectively analyze samples by IC, RDX samples treated with $\mathrm{MnO}_{4}{ }^{-}$were quenched with $\mathrm{MnCO}_{3}$.

Gas Chromatography/Electron Capture Detector (GC/ECD). Nitrous oxide $\left(\mathrm{N}_{2} \mathrm{O}\right)$ emitted from the $\mathrm{RDX}-\mathrm{MnO}_{4}-$ reaction was measured by direct injection into a Hewlett-Packard (Palo Alto, CA) 6890 GC operated with a HP-Plot column (Molecular sieve $5 A$ ) $30 \mathrm{~m} / 0.53 \mathrm{~mm}$ (50 $\mu \mathrm{m}$ film thickness) and electron capture detector (ECD). A P-5 gas (a mixture gas of $95 \%$ Argon and $5 \% \mathrm{CH}_{4}$ ) was used as a carrier gas for the GC system. The GC oven was equilibrated at least two hours at $225^{\circ} \mathrm{C}$ before analysis.

UV-Spectrophotometer. Changes in $\mathrm{MnO}_{4}{ }^{-}$concentrations were monitored by diluting solution with Ultra Pure water in $20-\mathrm{mL}$ vials and quantifying concentrations with a HACH Spectrophotometer DR2800 (HACH Company, Loveland, CO) at a wavelength of $525 \mathrm{~nm}$. A test of whether colloidal $\mathrm{MnO}_{2}$ interfered with quantification of $\mathrm{MnO}_{4}{ }^{-}$is presented in SI-3.

\section{Analysis of $\mathrm{N}$-containing gases.}

Nitrogen Gas $\left(N_{2}\right)$ To determine if $\mathrm{N}_{2}$ gas was a product of the RDX-MnO ${ }_{4}^{-}$ reaction, experiments were conducted under vacuum in a Rittenburg tube, a two-legged Y-shaped tube (Fig. S1), containing crystalline RDX (both ${ }^{14} \mathrm{~N}-\mathrm{RDX}$ and ${ }^{15} \mathrm{~N}-\mathrm{RDX}$ ) in one side and concentrated $\mathrm{MnO}_{4}{ }^{-}$solution in the other. Uniformly labeled, [U- $\left.{ }^{15} \mathrm{~N}\right] \mathrm{RDX}$, $\left({ }^{15} \mathrm{~N}\right.$ abundance of 97 atom\%) was purchased from PerkinEImer (Waltham, MA). Prior to starting the reaction (i.e., mixing), all gases were evacuated through a vacuum line Supporting Information for Chokejaroenrat et al./ ENVIRONMENTAL SCIENCE \& TECHNOLOGY SUBMISSION 
while the $\mathrm{MnO}_{4}$ solution was simultaneously frozen. Once the frozen solution melted, we mixed it with the crystalline RDX in the other side. The tube was then immersed in water $\left(\sim 20^{\circ} \mathrm{C}\right)$ to confirm no leakage and avoid atmospheric gas contamination. We also mirrored this experiment without vacuuming so as to monitor the RDX concentration by HPLC. When RDX was completely degraded, gas emission was drawn by a vacuum system passing through a cold trap to freeze all gases but $\mathrm{N}_{2}$ gas (Fig. S2; (1)). Gas samples were then collected in sample bulb and cryogenically transferred to an Optima Dual Inlet mass spectrometer (VG Isotech, Colchester, VT).

Results indicated that no increase in gas pressure was observed during the sample transfer and full scan measurement showed that, very little, if any $N_{2}$ gas $(m / z=$ $28,29,30$ ) formed during treatment. The primary reaction gas formed, $\mathrm{N}_{2} \mathrm{O}$, was trapped in the preparation line but was not analyzed on the instrument. 

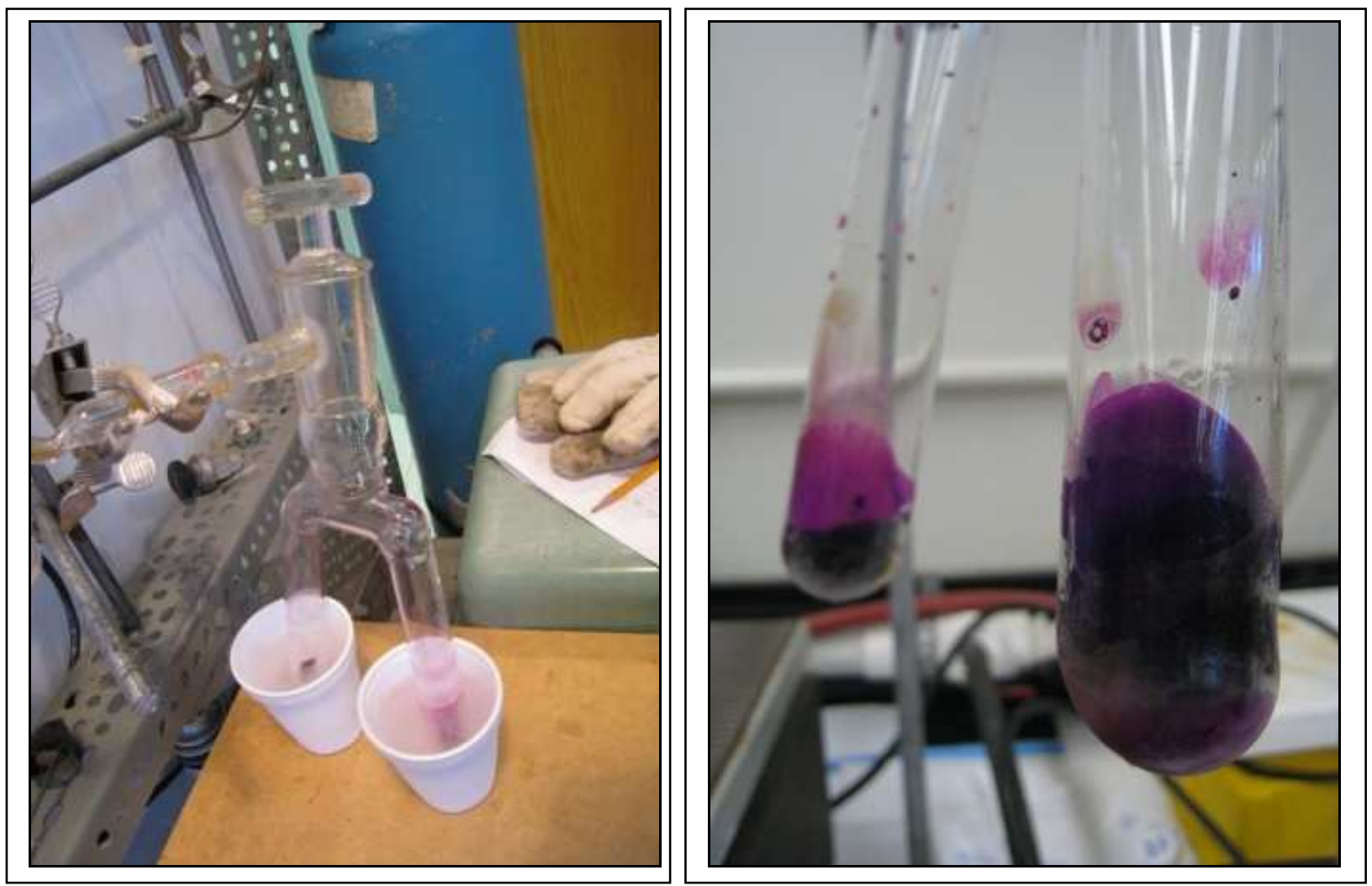

Figure S1: (Left) The Rittenburg tube containing $\mathrm{MnO}_{4}{ }^{-}$solution was frozen in liquid nitrogen while all gases were being vacuumed. (Right) thawed $\mathrm{RDX}-\mathrm{MnO}_{4}{ }^{-}$ solution after mixing. 


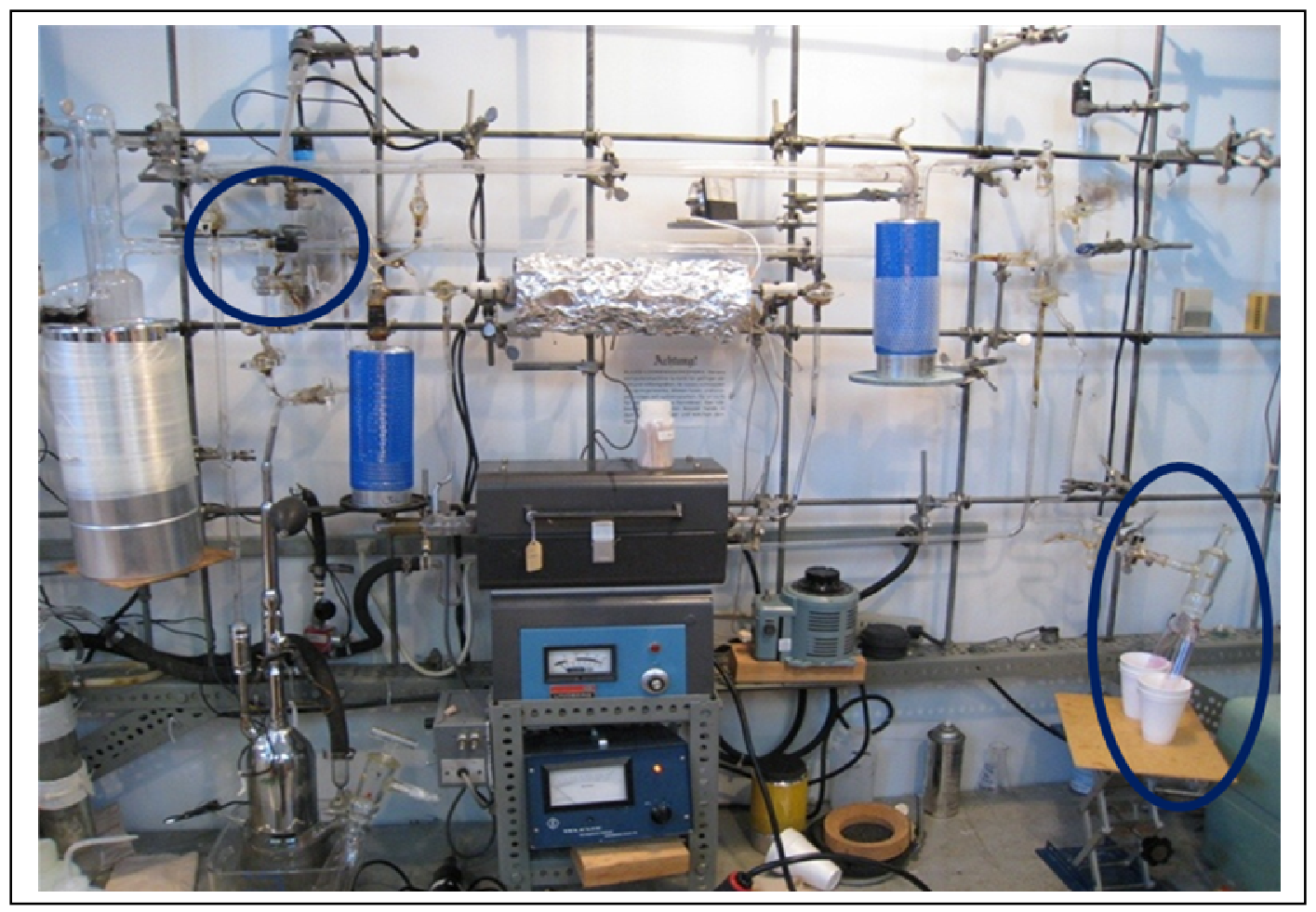

Figure S2: Experimental system for trapping of $\mathrm{N}_{2}$ gas. When RDX was completely degraded, all gases were evacuated from the Rittenburg tube (Lower Circle) and trapped in the vacuum system except $\mathrm{N}_{2}$ gas which was forced to the gas-tight sampling tube (Upper Circle).

$\underline{N O}_{x}$ gases (i.e., $\mathrm{NO}_{2}$ and $\mathrm{NO}$ ) Besides the $\mathrm{N}_{2}$ and $\mathrm{N}_{2} \mathrm{O}$ gases, we also investigated the production of $\mathrm{NO}_{x}$ gases (i.e., $\mathrm{NO}_{2}$ (nitrogen dioxide) and $\mathrm{NO}$ (nitric oxide)) to determine if they were released during the $\mathrm{RDX}-\mathrm{MnO}_{4}{ }^{-}$reaction. $\mathrm{NO}_{2}$ is known to produce from the reaction of concentrated nitric acid and copper and is a toxic brownish gas with a pungent acid odor. However, in the diluted solution of nitric acid and copper, water molecules cause the reaction to produce NO instead. Although we did not observe a distinct brownish color of $\mathrm{NO}_{2}$ during the $\mathrm{RDX}-\mathrm{MnO}_{4}{ }^{-}$reaction, we attempted to identify $\mathrm{NO}_{2}$ and other possible transformation products by treating $5 \mathrm{~mL}$ of 
saturated RDX (12.1 mg ${ }^{15} \mathrm{~N}$-labeled and $0.4 \mathrm{mg}$ non-labeled RDX) with $168.067 \mathrm{mM}$ of $\mathrm{MnO}_{4}{ }^{-}$in a 12-mL vial with a gastight septum. Each vial was degassed for 5 min and purged with Helium for 5 min by the acid injector (3.2 psi, Gilson, Middleton, WI) at a flow rate of $20.5 \mathrm{~mL} \mathrm{~min}^{-1}$. $\mathrm{NaMnO}_{4}(0.2 \mathrm{~mL}$ of $40 \%$ by weight) was injected into a vial by a gastight syringe. The temperature was controlled in a Precision 180 Series water bath at $60^{\circ} \mathrm{C}$ (Precision Scientific Co., Baltimore, MD) to increase RDX destruction rate. At $11 \mathrm{~d}$, a $10 \mu \mathrm{L}$ gas sample was removed from the vial and injected directly into a Hewlett-Packard 5890 GC (Palo Alto, CA) an Agilent 5972 quadrupole mass spectrometer. The $\mathrm{N}$ gases were separated on a $30 \mathrm{~m} / 0.32 \mathrm{~mm}$ PLOT Moleseive column (J\&W Scientific, Folsom, CA). The instrument was calibrated using Helium reference gas.

Results indicated that $\mathrm{NO}_{2}$ and $\mathrm{NO}$ were not detectable during the RDX-MnO${ }_{4}^{-}$ reaction. A complicating factor, however, is that if $\mathrm{NO}_{x}$ gasses (i.e., $\mathrm{NO}$ or $\mathrm{NO}_{2}$ ) are liberated during the treatment of $\mathrm{RDX}$ with $\mathrm{MnO}_{4}{ }^{-}$, it will be difficult to quantify because $\mathrm{MnO}_{4}^{-}$provides an excellent means of removing $\mathrm{NO}$ by oxidizing it to $\mathrm{NO}_{2}^{-}$and $\mathrm{NO}_{3}^{-}$, depending on $\mathrm{pH}(2-4)$. Alkaline or acidic $\mathrm{MnO}_{4}{ }^{-}$has also been shown to be capable of trapping $\mathrm{NO}_{\times}$gas emission from soils $(5-8)$. 


\section{SI-2. RDX Purification}

The commercial grade RDX contains $\sim 90 \%$ RDX and $\sim 10 \%$ HMX (octahydro1,3,5,7-tetranitro-1,3,5,7-tetrazocine). To remove interferences and degradation artifacts associated with HMX, we removed the HMX by preparing a concentrated RDX solution (in acetonitrile) and purified to $\geq 99 \%$ RDX by using a Waters 2695 HPLC (Waters Corp., Milford, MA) with a temperature-controlled $\left(30^{\circ} \mathrm{C}\right)$ Kromasil C18 column, $250 \times 4.6 \mathrm{~mm}$, (Thermo Scientific, MA) and Photodiode Array Detector (Waters 2996, Waters Corp., Milford, MA). The flow rate for this purification procedure was $1.5 \mathrm{~mL} / \mathrm{min}$ with a repeated injection volume of $25 \mu \mathrm{L}$. A mobile phase of methanol (in $\mathrm{H}_{2} \mathrm{O}$ ) was used with the following gradient: 60:40 for 9 min followed by $90: 10$ for 3.5 min and $60: 40$ for the remainder of the run ( 7.5 min). A Spectrum CF-2 fraction collector was used to isolate the RDX peak eluting from the column. The RDX fractions were combined and concentrated by the RapidVap evaporation system (Labconco, Kansas city, MO) in which a cylindrical receptacle was swirled and blown by $\mathrm{N}_{2}$ gas at $50^{\circ} \mathrm{C}$ until dry. 


\section{SI-3. Experimental Controls}

A series of experiments were performed under batch conditions to verify that RDX destruction rates by $\mathrm{MnO}_{4}{ }^{-}$were similar when the initial $\mathrm{pH}$ was controlled or allowed to drift as the reaction proceeded (Fig. S3), the use of $\mathrm{MnCO}_{3}$ as a quenching agent did not significantly influence sample $\mathrm{pH}$ or temperature (Table S1), RDX concentrations after quenching with $\mathrm{MnCO}_{3}$ were stable and not subject to hydrolysis (Fig. S4), and that quantification of $\mathrm{MnO}_{4}{ }^{-}$concentrations were not influenced by colloidal $\mathrm{MnO}_{2}$ (Fig. S5).

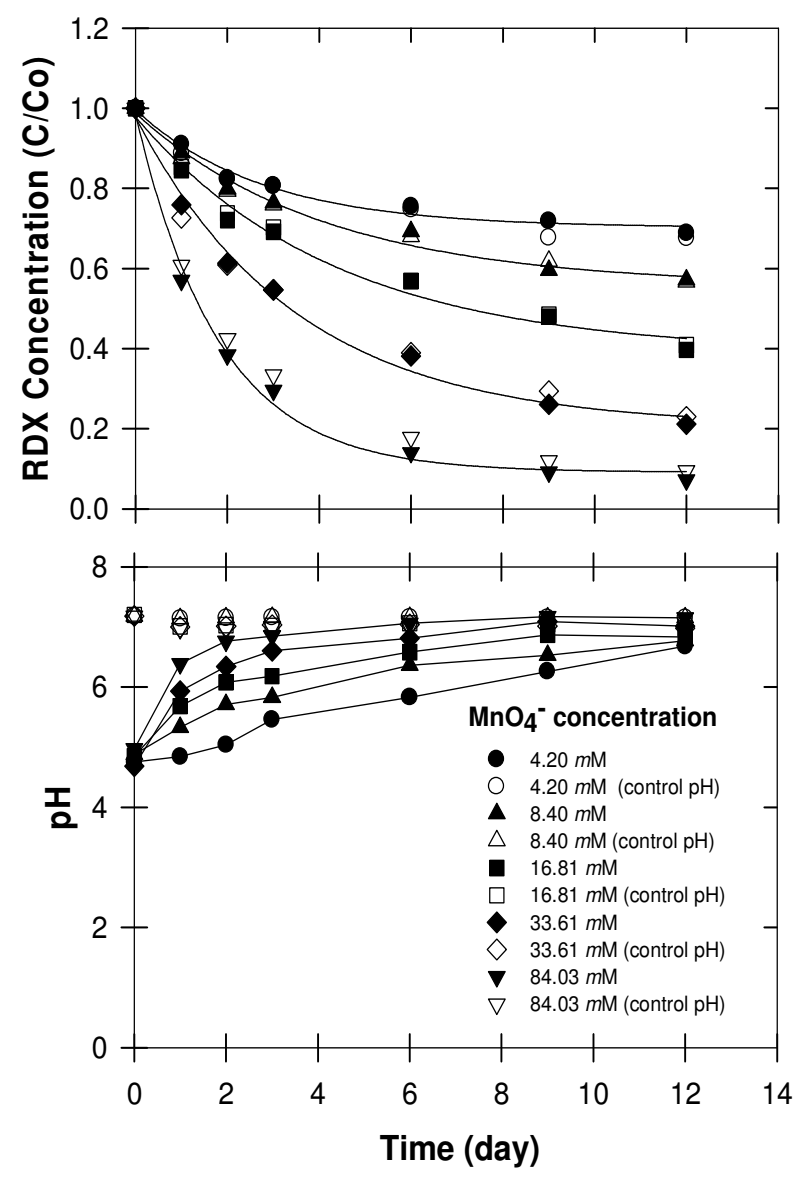

Figure S3. Changes in RDX concentration and $\mathrm{pH}$ by various concentrations of $\mathrm{MnO}_{4}{ }^{-}$ under controlled and unbuffered $\mathrm{pH}$. 
Table S1. Changes in $\mathrm{pH}$ and temperature of $\mathrm{RDX}-\mathrm{MnO}_{4}{ }^{-}$solution following quenching with various mass of $\mathrm{MnCO}_{3}$.

\begin{tabular}{ccccc}
\hline $\begin{array}{c}\text { MnCO before } \\
\mathrm{MnC}_{3}\end{array}$ & $\begin{array}{c}\mathrm{pH} \text { after } \\
\text { quenching } \\
\text { quen } \mathrm{mL} \text { of } \\
\text { sample) }\end{array}$ & $\begin{array}{c}\text { Temp before } \\
\text { quenching }\end{array}$ & $\begin{array}{c}\text { Temp after } \\
\text { quenching }\end{array}$ \\
$0.00 \mathrm{~g}$ & 5.88 & & $\left({ }^{\circ} \mathrm{C}\right)$ & $\left({ }^{\circ} \mathrm{C}\right)$ \\
$0.03 \mathrm{~g}$ & 5.82 & 6.15 & 25 & \\
$0.04 \mathrm{~g}$ & 5.81 & 6.02 & 25 & 24 \\
$0.05 \mathrm{~g}$ & 5.85 & 6.02 & 25 & 23 \\
$0.06 \mathrm{~g}$ & 5.80 & 5.93 & 25 & 23 \\
$0.07 \mathrm{~g}$ & 5.74 & 5.86 & 25 & 22.5 \\
& & & & \\
\hline
\end{tabular}




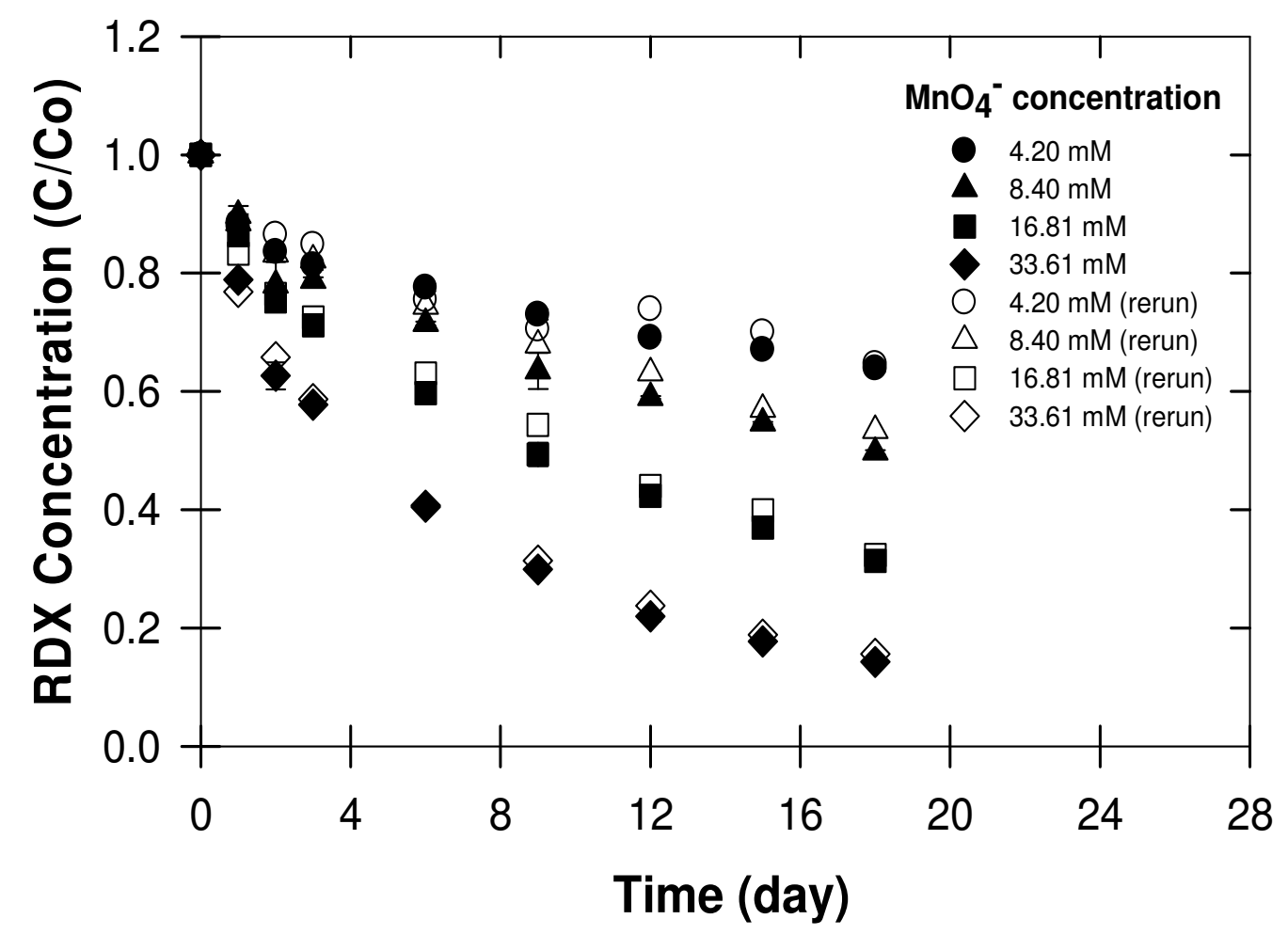

Figure S4. Temporal changes in RDX concentrations following treatment with varying $\mathrm{MnO}_{4}^{-}$concentrations. Solid symbols signify concentrations of samples analyzed immediately, open symbols are the same samples analyzed $9 \mathrm{~d}$ later. 

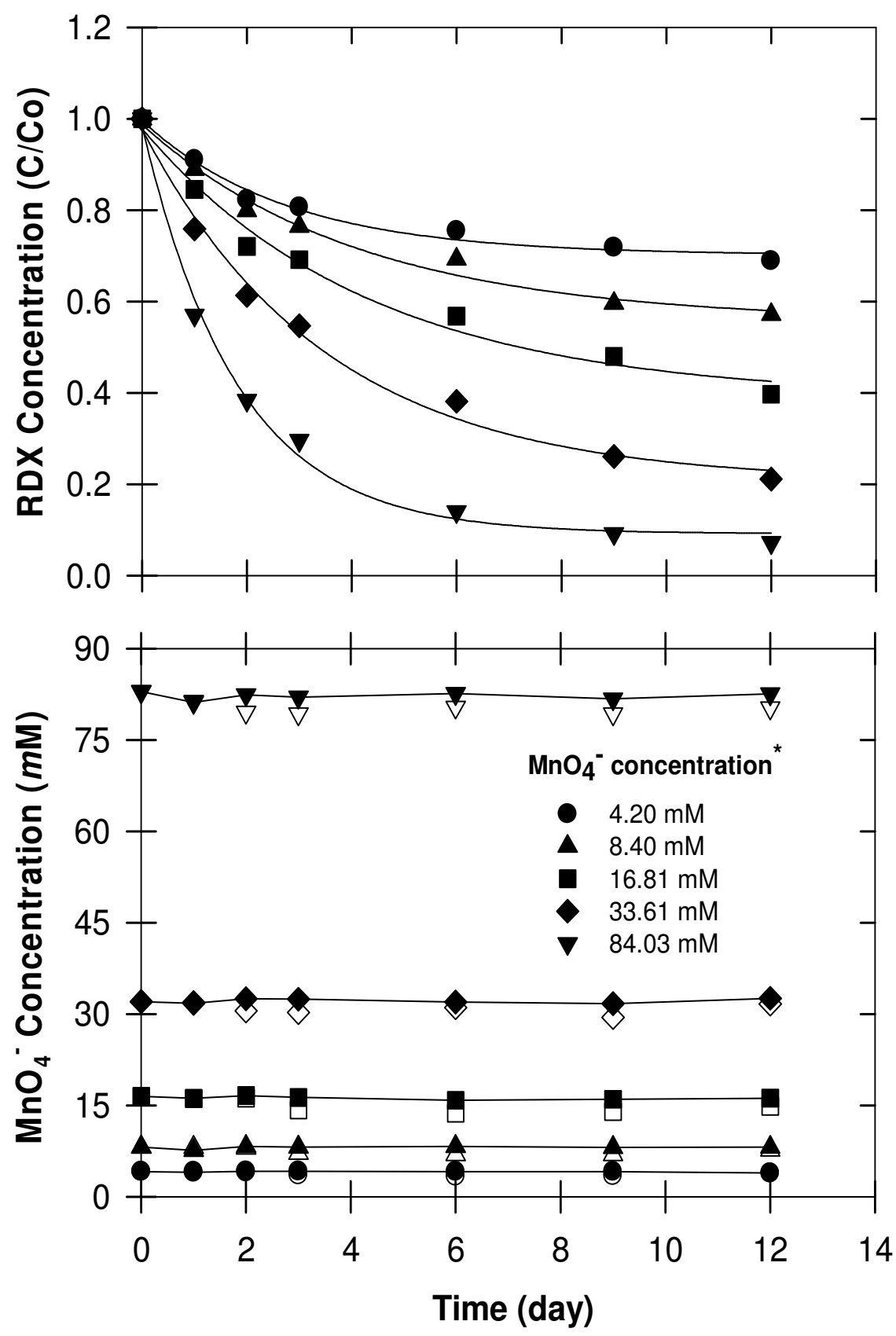

Figure S5. Changes in $\mathrm{RDX}$ and $\mathrm{MnO}_{4}{ }^{-}$concentrations following treatment with varying $\mathrm{MnO}_{4}{ }^{-}$concentrations. Solid symbols indicate $\mathrm{MnO}_{4}{ }^{-}$concentrations determined without filtration, open symbols with filtration $(0.45 \mu \mathrm{m}$ glasswool filter). 


\section{SI-4. Effect of quenching agents on RDX degradation products}

To determine the effect of quenching agents on RDX degradation products, aqueous solutions of $\mathrm{RDX}(0.07 \mathrm{mM})$ were treated with $33.61 \mathrm{mM}$ of $\mathrm{MnO}_{4}{ }^{-}$. We initially prepared RDX solutions by spiking $150 \mathrm{~mL} \mathrm{H}_{2} \mathrm{O}$ with $1.04 \mathrm{~mL}$ of RDX stock solutions prepared in acetone but the acetone- $\mathrm{MnO}_{4}{ }^{-}$reaction resulted in autocatalysis of $\mathrm{MnO}_{4}{ }^{-}$ at alkaline $\mathrm{pH}$ and prevented further degradation of RDX $>10 \mathrm{~d}$ (see Supporting Information; SI-5). Consequently, all aqueous RDX solutions were prepared by dissolving purified crystalline RDX in water over several days. Once $\mathrm{MnO}_{4}{ }^{-}$was added to RDX solutions to initiate the reaction, samples were periodically collected and quenched with $\mathrm{MnCO}_{3}$ or $\mathrm{H}_{2} \mathrm{O}_{2}$. Quenching with $\mathrm{MnCO}_{3}(\mathrm{pH}=6.7)$ was performed as described in the main manuscript. When quenched with $30 \% \mathrm{H}_{2} \mathrm{O}_{2}(0.04 \mathrm{~mL}$ per $\mathrm{mL}$ of sample), samples were required to mix continuously to control $\mathrm{H}_{2} \mathrm{O}_{2}$ consumption. The $\mathrm{pH}$ of samples quenched with $\mathrm{H}_{2} \mathrm{O}_{2}$ were found to increase significantly $(\mathrm{pH}=11.5)$. To elucidate this $\mathrm{pH}$ effect, one set of batch samples were quenched with $\mathrm{MnCO}_{3}$, and we increased the $\mathrm{pH}$ to that observed with the $\mathrm{H}_{2} \mathrm{O}_{2}$ by adding $\mathrm{NaOH}$. Temporal changes in RDX, 4-nitro-2,4-diazabutanal (4-NDAB), $\mathrm{NO}_{3}{ }^{-}$, and $\mathrm{NO}_{2}{ }^{-}$concentration were monitored by using HPLC and IC.

Results indicated that an RDX solution treated with $\mathrm{MnO}_{4}{ }^{-}$led to complete RDX transformation within $15 \mathrm{~d}$ (Fig. S6A). To quantify temporal changes in RDX concentrations, samples were removed from the batch reactors every 2 to $3 \mathrm{~d}$ and chemically quenched to remove $\mathrm{MnO}_{4}^{-}$and prevent further RDX oxidation. While $\mathrm{MnSO}_{4}$ is commonly used as a quenching agent (9-13) and does not interfere in HPLC analysis of RDX (12-13), the sulfate liberated interferes with $\mathrm{NO}_{2}{ }^{-}$and $\mathrm{NO}_{3}{ }^{-}$analyses by ion chromatography (IC). By using $\mathrm{MnCO}_{3}$, we avoided this interference during IC analysis. However, the disadvantage of using $\mathrm{MnCO}_{3}$ is that, at the concentrations of 
quenching agents used, $\mathrm{MnCO}_{3}$ takes longer than $\mathrm{MnSO}_{4}$ to quench the $\mathrm{MnO}_{4}^{-}$. Given the typical time course of the batch experiments ( $15 \mathrm{~d})$, we compared RDX destruction rates from the same batch experiment and observed similar RDX destruction rates (Fig. S7).

Another consideration is that the quenching agent can alter the $\mathrm{pH}$ of the sample and possibly influence product formation or stability. When samples were quenched with $\mathrm{MnSO}_{4}$, solution $\mathrm{pH}$ decreased from $~ 7.2$ (before quenching) to $\mathrm{pH} 2.6$ after quenching as predicted by the following reaction (Eq. S1).

$$
2 \mathrm{NaMnO}_{4}+3 \mathrm{MnSO}_{4}+2 \mathrm{H}_{2} \mathrm{O} \rightarrow 2 \mathrm{Na}^{+}+3 \mathrm{SO}_{4}{ }^{2-}+4 \mathrm{H}^{+}+5 \mathrm{MnO}_{2}
$$

When $\mathrm{RDX}-\mathrm{MnO}_{4}-$ solutions were quenched with $\mathrm{MnCO}_{3}$ (Eq. S2), sample $\mathrm{pH}$ (after quenching) remained near 6.7, which is closer to the $\mathrm{pH}$ of the unquenched RDX$\mathrm{MnO}_{4}{ }^{-}$solution.

$$
2 \mathrm{NaMnO}_{4}+3 \mathrm{MnCO}_{3}+2 \mathrm{H}_{2} \mathrm{O} \rightarrow 2 \mathrm{Na}^{+}+3 \mathrm{HCO}_{3}^{-}+5 \mathrm{MnO}_{2}+\mathrm{H}^{+}
$$

Product analysis during the $\mathrm{RDX}-\mathrm{MnO}_{4}-$ reaction showed that when $\mathrm{MnCO}_{3}$ was used as a quenching agent, we observed $\mathrm{NO}_{3}{ }^{-}$production in the reaction but no $\mathrm{NO}_{2}{ }^{-}$ and only a trace of 4-NDAB ( 0.004 mM) (Fig. S6A).

Peroxide was also used as a quenching agent. Here, peroxide reacts with $\mathrm{MnO}_{4}{ }^{-}$ by the following reaction (Eq. S3):

$$
2 \mathrm{NaMnO}_{4}+4 \mathrm{H}_{2} \mathrm{O}_{2} \rightarrow 2 \mathrm{Na}^{+}+2 \mathrm{OH}^{-}+\mathrm{Mn}_{2} \mathrm{O}_{3}+3 \mathrm{H}_{2} \mathrm{O}+4 \mathrm{O}_{2}
$$

Because $\mathrm{OH}^{-}$is liberated, the $\mathrm{pH}$ of samples quenched with $\mathrm{H}_{2} \mathrm{O}_{2}$ increased $(\mathrm{pH}$ 
11.5) and we observed $\mathrm{NO}_{2}{ }^{-}, \mathrm{NO}_{3}{ }^{-}$, and 4-NDAB (Fig. S6B). Although the magnitude of $\mathrm{NO}_{3}{ }^{-}$generated was similar to what we observed when $\mathrm{MnCO}_{3}$ was used as a quenching agent (Fig. S6A, S6B), RDX destruction kinetics were much faster $(k=1.83$ $\left.d^{-1}\right)$. Because we suspected excess peroxide may have contributed to RDX destruction, we conducted an experiment where RDX solution was treated with $\mathrm{H}_{2} \mathrm{O}_{2}$ in the same ratio as used in quenching process $\left(0.04 \mathrm{~mL}\right.$ of $30 \% \mathrm{H}_{2} \mathrm{O}_{2}$ to $1 \mathrm{~mL} R D X$ or $1.2 \%(\mathrm{v} / \mathrm{v})$ $\mathrm{H}_{2} \mathrm{O}_{2} ;$ no $\mathrm{MnO}_{4}{ }^{-}$). Results showed that RDX concentration was not significantly affected, $\mathrm{pH}$ remained constant, and $\mathrm{RDX}$ degradation products $\left(\mathrm{NO}_{2}^{-} \mathrm{NO}_{3}^{-}\right.$, and 4-NDAB) were not observed.

The peroxide concentration used in this control experiment ( $\mathrm{RDX}+\mathrm{H}_{2} \mathrm{O}_{2}$ only) was higher than what the quenched $\mathrm{RDX}-\mathrm{MnO}_{4}{ }^{-}$samples would have experienced because most, if not all, of the $\mathrm{H}_{2} \mathrm{O}_{2}$ would have reacted with the $\mathrm{MnO}_{4}$. Therefore, the increased RDX destruction kinetics observed (Fig. S6B) does not appear to be directly related to the presence of excess peroxide. Rather, catalytic decomposition of $\mathrm{H}_{2} \mathrm{O}_{2}$ into various radicals (i.e., superoxide anion $\left(\mathrm{O}_{2}{ }^{-}\right)$, hydroperoxide radical $\left(\mathrm{HO}_{2}{ }^{\bullet}\right)$, and hydroxyl radical $(\cdot \mathrm{OH})$ ) may have played a role in the enhanced degradation of RDX (Fig. S6B). Although $\mathrm{MnO}_{2}$ surfaces can enhance oxidation reactions (14), this precipitate, which forms during $\mathrm{RDX}-\mathrm{MnO}_{4}{ }^{-}$reaction (12), is also a catalyst for decomposition of $\mathrm{H}_{2} \mathrm{O}_{2}$ and both $\mathrm{O}_{2}^{-}$and $\mathrm{HO}_{2} \cdot$ are favored at high $\mathrm{pH}(15-16) . \mathrm{O}_{2}{ }^{-}$itself is known to be capable of degrading RDX (17). Furthermore, during the quenching process, $\mathrm{Mn}_{2} \mathrm{O}_{3}$ is liberated (Eq. S3) and can simultaneously act as a catalyst for degradation of organic compounds in the presence of $\mathrm{H}_{2} \mathrm{O}_{2}(15,18)$. Another possibility is that the alkaline $\mathrm{pH}$ created during the quenching process (Eq. S3) facilitated $\mathrm{H}_{2} \mathrm{O}_{2}$ decomposition into $\cdot \mathrm{OH}$ which contributed to RDX degradation. Moreover, Gates-Anderson et al. (19) observed that in strongly basic solutions $(\mathrm{pH}>9) \cdot \mathrm{OH}$ can also be generated from $\mathrm{MnO}_{4}{ }^{-}$and directly oxidize organic contaminants. These explanations support a seven-fold increase of 
RDX destruction kinetics (Figs. S6A, S6B).

Finally, an elevated temperature may also have been responsible for greater RDX destruction in the $\mathrm{H}_{2} \mathrm{O}_{2}$ quenched samples. Heilmann et al. (20) showed that alkaline hydrolysis rates of RDX in aqueous solution dramatically increased at high temperature $\left(50^{\circ} \mathrm{C}\right)$. We observed that using $\mathrm{H}_{2} \mathrm{O}_{2}$ as a quenching agent caused a rapid $9^{\circ} \mathrm{C}$ increase in sample temperatures. Because $\mathrm{H}_{2} \mathrm{O}_{2}-\mathrm{MnO}_{4}-$ reaction is exothermic, it is reasonable that the combination of alkaline $\mathrm{pH}$ and heat may have contributed to RDX degradation (See also Effect of Temperature on $\mathrm{RDX}-\mathrm{MnO}_{4}^{-}$Reaction in the main manuscript).

Given that the treatment of RDX with peroxide alone did not cause an increase in $\mathrm{pH}$ or the production of $\mathrm{NO}_{2}^{-}$and 4-NDAB, the alkaline $\mathrm{pH}$ created by the $\mathrm{H}_{2} \mathrm{O}_{2}-\mathrm{MnO}_{4}{ }^{-}$ reaction was likely responsible for the degradation products observed. To test this further, we again used $\mathrm{MnCO}_{3}$ as a quenching agent and artificially raised the $\mathrm{pH}$ of the samples before and after quenching to $\mathrm{pH} 11.5$ (similar to what was observed with $\mathrm{H}_{2} \mathrm{O}_{2}$ as a quenching agent). Results showed RDX degradation was slower than when peroxide was used to quench the $\mathrm{MnO}_{4}{ }^{-}$and closer to the results obtained when $\mathrm{MnCO}_{3}$ was used without $\mathrm{pH}$ adjustment (Fig. S6A, $k=0.26 \mathrm{~d}^{-1}$; Fig. S6C, $k=0.33 \mathrm{~d}^{-1}$ ). This observation lends credence to the possibility that peroxide radicals may have been involved during the quenching of $\mathrm{MnO}_{4}{ }^{-}$with $\mathrm{H}_{2} \mathrm{O}_{2}$ (Fig. S6B). Using $\mathrm{MnCO}_{3}+$ alkaline $\mathrm{pH}$ also produced $\mathrm{NO}_{2}^{-}$and 4-NDAB as reaction products (Fig. S6C). Two known RDX degradation schemes involve the removal of one nitro group (denitration) with the intermediate methylenedintramine (MEDINA) or two nitro groups and the formation of 4$\operatorname{NDAB}$ (e.g. (21)). Thus, the detection of nitrite during the $\mathrm{RDX}-\mathrm{MnO}_{4}^{-}$reaction (with $\mathrm{H}_{2} \mathrm{O}_{2}$ quenching agent or $\mathrm{MnCO}_{3}+$ alkaline $\mathrm{pH}$ ) is likely a result of the alkalinity stabilizing $\mathrm{NO}_{2}^{-}$and preventing further transformation. Numerous reports have shown 
that nitrite is more persistent at alkaline $\mathrm{pH}$ (22-23). Balakrishnan et al. (24) also found $\mathrm{NO}_{2}^{-}$as an endproduct of RDX hydrolysis.

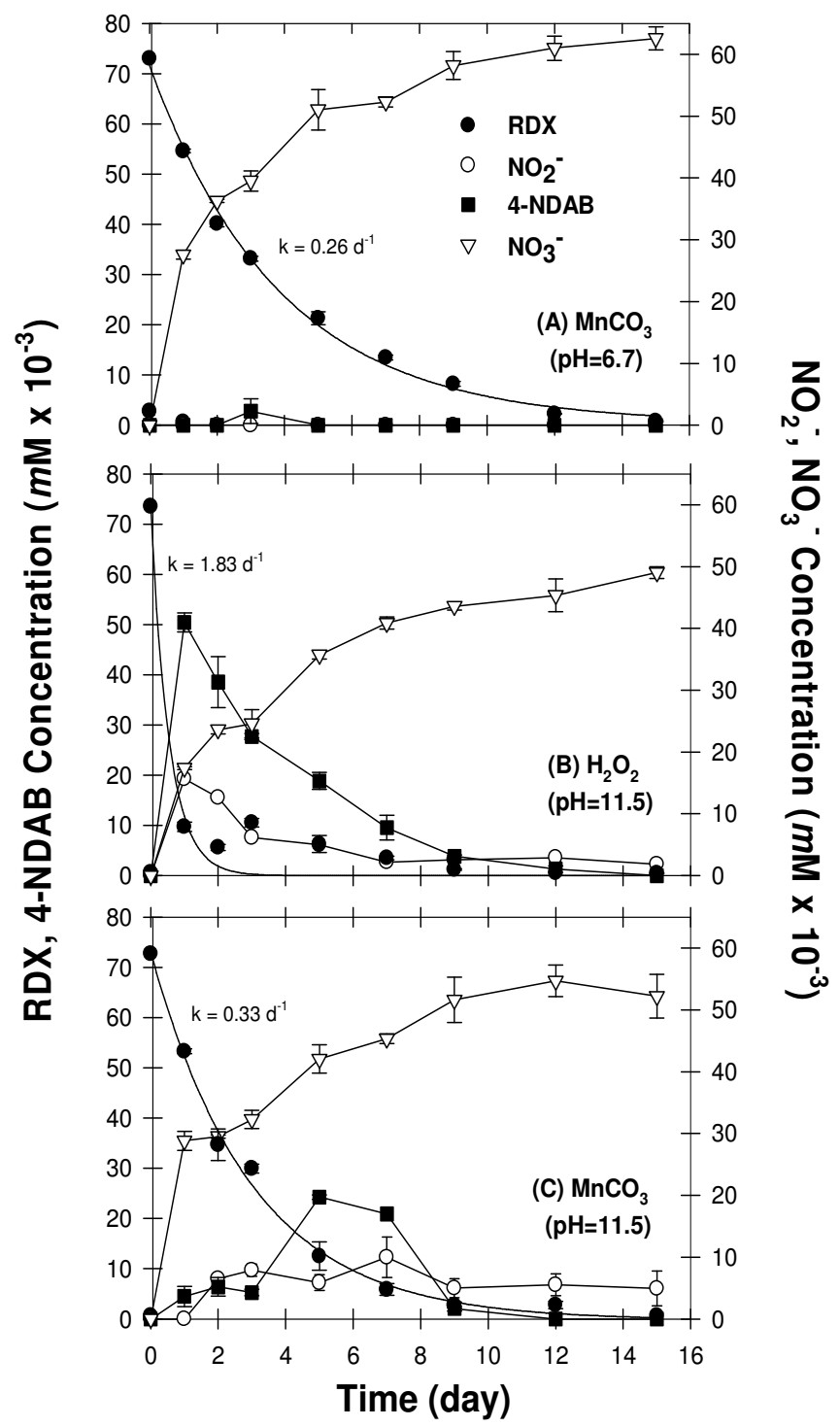

Figure S6: Changes in mux concenuramon anu prouucuon ol aegradation products (4$\mathrm{NDAB}, \mathrm{NO}_{2}^{-}$, and $\mathrm{NO}_{3}^{-}$) when quenched with; (A) $0.10 \mathrm{~g} \mathrm{MnCO}_{3}$ (per $\mathrm{mL}$ ); (B) $0.04 \mathrm{ml} \mathrm{30 \%} \mathrm{H}_{2} \mathrm{O}_{2}$ (per $\mathrm{mL}, \mathrm{pH} \sim 11.5$ ); and (C) $0.10 \mathrm{~g} \mathrm{MnCO}_{3}$ (per $\mathrm{mL}$ ) in which sample solutions $\mathrm{pH}$ was raised to 11.5 before and after quenching. Bars indicate sample standard deviations $(n=3)$. 


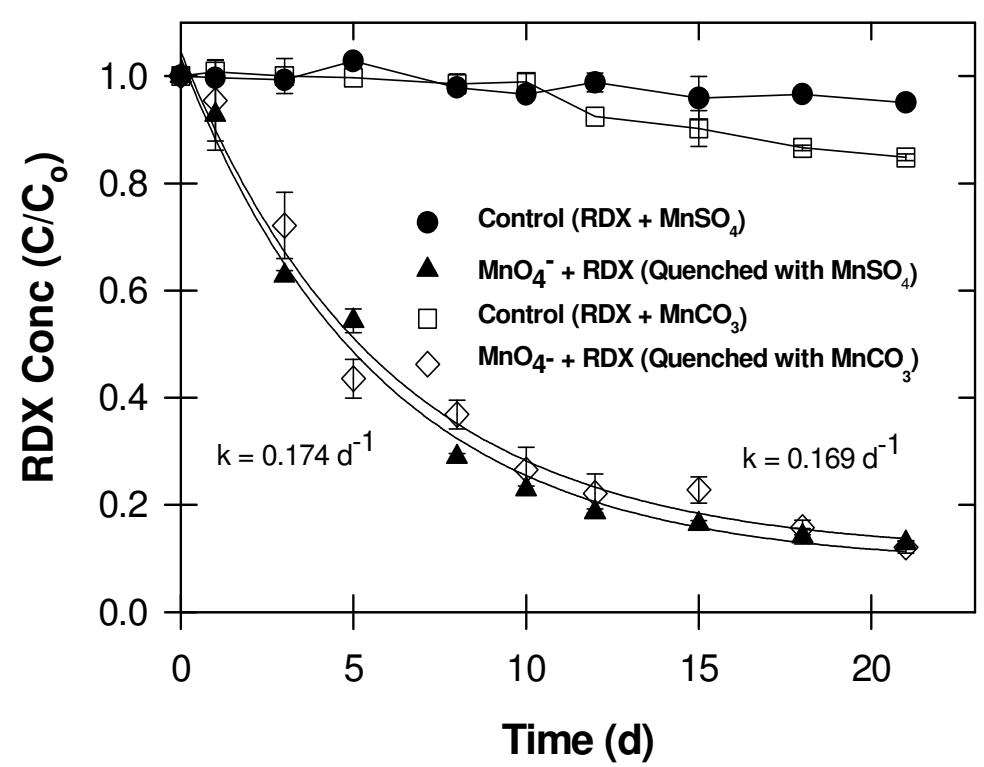

Figure S7: Comparison of RDX degradation kinetic rates when quenched with $\mathrm{MnSO}_{4}$ or $\mathrm{MnCO}_{3}$. Bars indicate sample standard deviations $(\mathrm{n}=3)$.

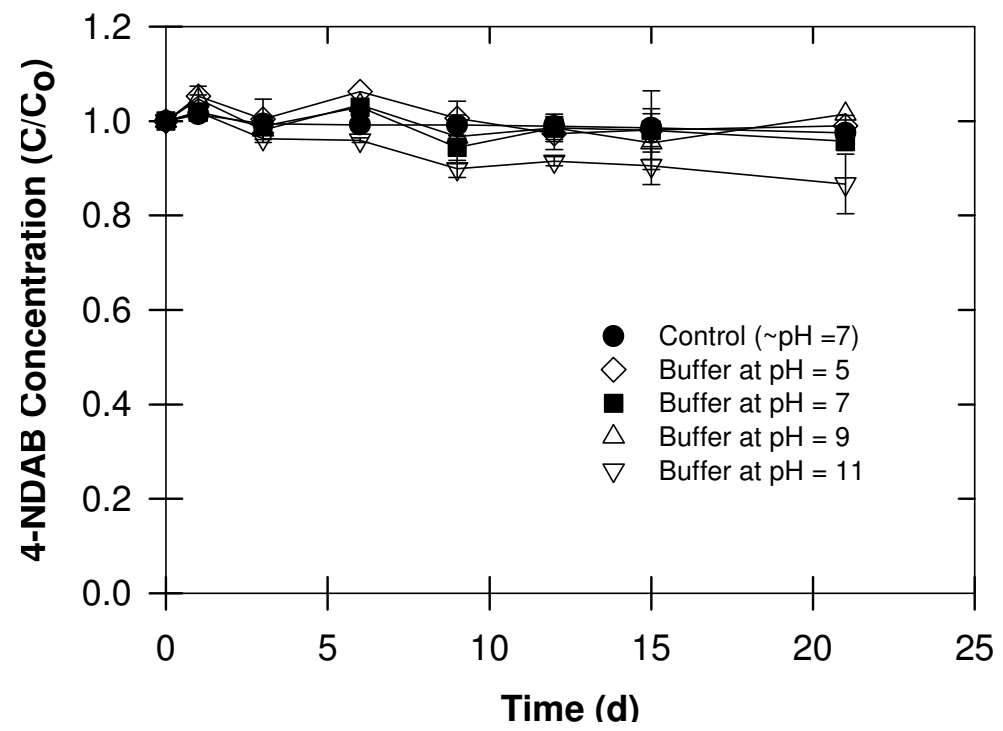

Figure S8: The effect of $\mathrm{pH}$ on 4-NDAB stability. Bars indicate sample standard deviations $(n=3)$. 


\section{SI-5. RDX Batch Experiments (Facilitated Decomposition of permanganate)}

To evaluate the effects of initial $\mathrm{MnO}_{4}{ }^{-}$concentration on RDX destruction rates, we conducted the batch experiment by treating $150 \mathrm{~mL}$ of aqueous ${ }^{14} \mathrm{C}-\mathrm{RDX}(0.02 \mathrm{mM}$,

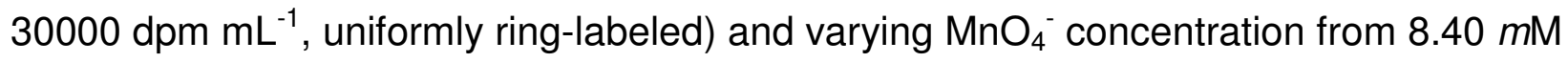
to $168.07 \mathrm{mM}$. Each $\mathrm{MnO}_{4}{ }^{-}$concentration was replicated three times. Temporal samples were periodically collected and quenched with $\mathrm{MnSO}_{4}$ as described in analytical section and monitored for the loss of RDX by HPLC and ${ }^{14} \mathrm{C}$-activity by Liquid Scintillation Counter (LSC).

Results indicated that treating aqueous (i.e., distilled water) RDX with 168.067 $\mathrm{mM}$ of $\mathrm{MnO}_{4}{ }^{-}$reduced RDX concentrations to zero within $10 \mathrm{~d}\left(k=0.49 \mathrm{~d}^{-1}\right)$ (Fig. S9A). Lower $\mathrm{MnO}_{4}{ }^{-}$concentrations $(8.40-42.02 \mathrm{mM})$ reduced $\mathrm{RDX}$ destruction rates and overall removal. For instance, when RDX was treated with $8.40 \mathrm{mM}$ of $\mathrm{MnO}_{4}^{-}$ destruction rates decreased $\sim 70 \%\left(k=0.14 \mathrm{~d}^{-1}\right)$ and only $29 \%$ of the initial RDX was removed within $10 \mathrm{~d}$ (25). These results are similar to those reported by Adam et al. (12) but differ in that temporal decrease in both RDX and ${ }^{14} \mathrm{C}$ concentrations (Fig. S9B) reached a plateau after $\sim 10 \mathrm{~d}$. The reasons $\mathrm{MnO}_{4}^{-}$failed to continually transform and mineralize RDX beyond $10 \mathrm{~d}$ was investigated by monitoring temporal changes in $\mathrm{pH}$ and $\mathrm{MnO}_{4}{ }^{-}$concentrations.

By repeating the experiment with $84.03 \mathrm{mM}$ of $\mathrm{MnO}_{4}{ }^{-}$and monitoring $\mathrm{MnO}_{4}{ }^{-}$and $\mathrm{pH}$ (Fig. S10A, S10B, S10C), we observed an increase in $\mathrm{pH}$ from 6.5 to $>8$. Using higher $\mathrm{MnO}_{4}{ }^{-}$concentrations $(126.05,168.07 \mathrm{mM}$ ) also produced similar changes in $\mathrm{pH}$. This increase in $\mathrm{pH}$ coincided with a significant decrease in $\mathrm{MnO}_{4}{ }^{-}$concentration (Fig. S10B). By contrast, when a pH-stat (Metrohm Titrino 718S; Brinkman Instruments, Westbury) maintained the $\mathrm{pH}$ at $7, \mathrm{RDX}$ concentrations did not plateau but continued to decrease and very little consumption of $\mathrm{MnO}_{4}{ }^{-}$was observed (Fig. S10A, S10B). It is clear that in the unbuffered treatment, the rapid decrease in $\mathrm{MnO}_{4}^{-}$concentration 
coincided with the lack of further RDX destruction beyond $7 \mathrm{~d}$ (i.e., plateau). We believe the loss of $\mathrm{MnO}_{4}{ }^{-}$was likely caused by a facilitated decomposition of permanganate at alkaline $\mathrm{pH}$. But alkaline $\mathrm{pH}$ alone was not solely responsible for the loss of $\mathrm{MnO}_{4}{ }^{-}$. Adam et al. (12) evaluated the effect of $\mathrm{pH}$ on RDX destruction kinetics and reported no $\mathrm{pH}$ effect in the range 4.1 to 11.3. A comparison of procedures used by Adam et al. (12) and our protocol revealed that a higher percentage of acetone was used in our batch reactors. This occurred by using RDX stock solutions prepared in acetone (both unlabeled and ${ }^{14} \mathrm{C}$-labeled) to spike the aqueous solutions with RDX. Although the volume of acetone spiked into the aqueous batch reactors was relatively low $(1.04 \mathrm{~mL}$ acetone/150 $\mathrm{mL} \mathrm{H} \mathrm{H}_{2} \mathrm{O}$ ), when this same concentration of acetone was added to 84.03 $m \mathrm{M}$ of $\mathrm{MnO}_{4}^{-}$without RDX, a similar decrease in $\mathrm{MnO}_{4}^{-}$was observed (Fig. S10D, S10E, S10F); similarly, when aqueous RDX solutions were prepared without acetone, the $\mathrm{pH}$ remained constant (Fig. $\mathrm{S} 10 \mathrm{~F}$ ) and $\mathrm{MnO}_{4}{ }^{-}$consumption was negligible (Fig. S10E). The plateau in RDX loss observed (Figs. S9, S10) resulted from the reaction of acetone with $\mathrm{MnO}_{4}{ }^{-}$and likely included the oxidation of acetone to oxalic acid and the reaction of oxalic acid with $\mathrm{MnO}_{4}^{-}$to form $\mathrm{Mn}^{2+}$, which is known to facilitate the decomposition of $\mathrm{MnO}_{4}$.

While the accelerated removal of $\mathrm{MnO}_{4}{ }^{-}$was traced back to the use of acetone and subsequent formation of carboxylic acids in our batch reactors (Fig. S10), the implications of this observation may be more than just an experimental anomaly. Oxalic acid is a product of the $\mathrm{TCE}^{-} \mathrm{MnO}_{4}$ reaction (26). Li et al. (27) also showed that oxalate was a primary oxidation product of the explosive TNT (2,4,6-trinitrotoluene) during treatment with $\mathrm{Fe}^{2+}$ and $\mathrm{H}_{2} \mathrm{O}_{2}$ (i.e., Fenton oxidation). Thus, situations may arise where oxalate (or other carboxylic acids) are present and cause excessive $\mathrm{MnO}_{4}{ }^{-}$ decomposition if the $\mathrm{pH}$ is not monitored and prevented from becoming alkaline. 


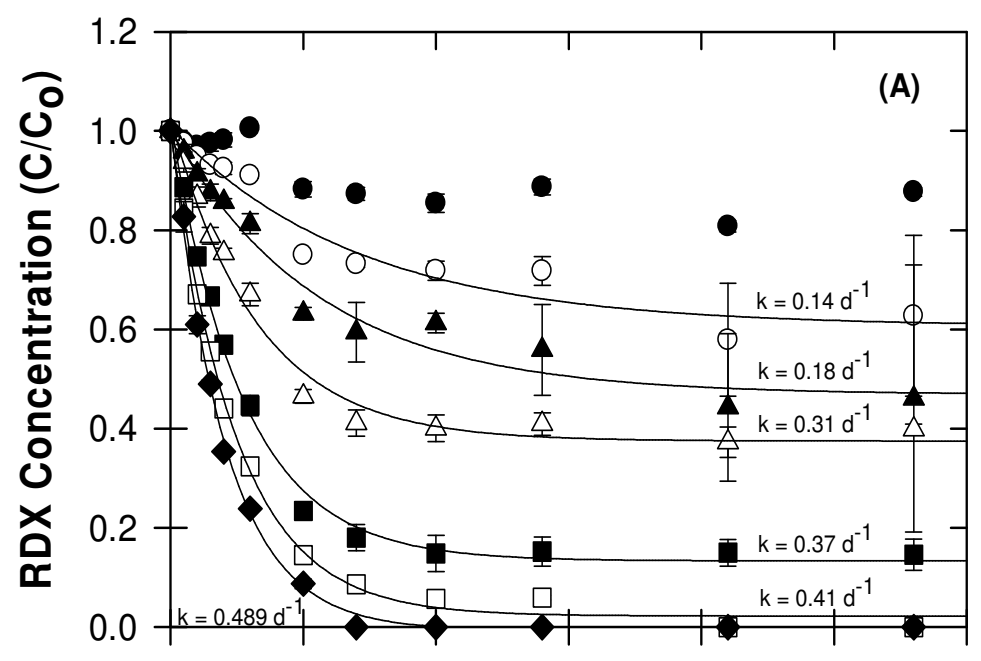

$\mathrm{MnO}_{4}^{-}$Conc.

- Control

○ $8.40 \mathrm{mM}$

$\Delta 21.01 \mathrm{mM}$

$\triangle \quad 42.02 \mathrm{mM}$

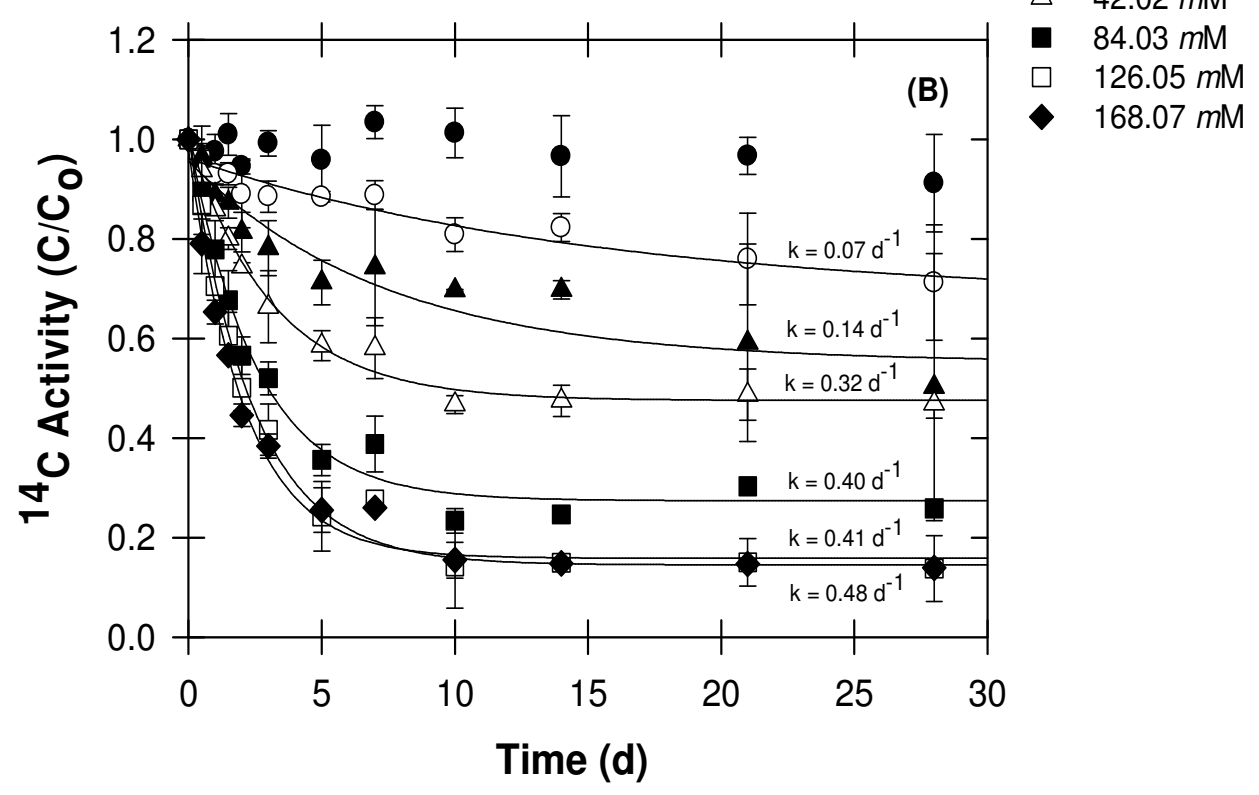

Figure S9: Loss of $\mathrm{RDX}$ and ${ }^{14} \mathrm{C}$-activity in aqueous solution treated with various concentrations of $\mathrm{MnO}_{4}{ }^{-}$. Solution samples were quenched with $\mathrm{MnSO}_{4}$. Bars indicate sample standard deviations $(n=3)$. 


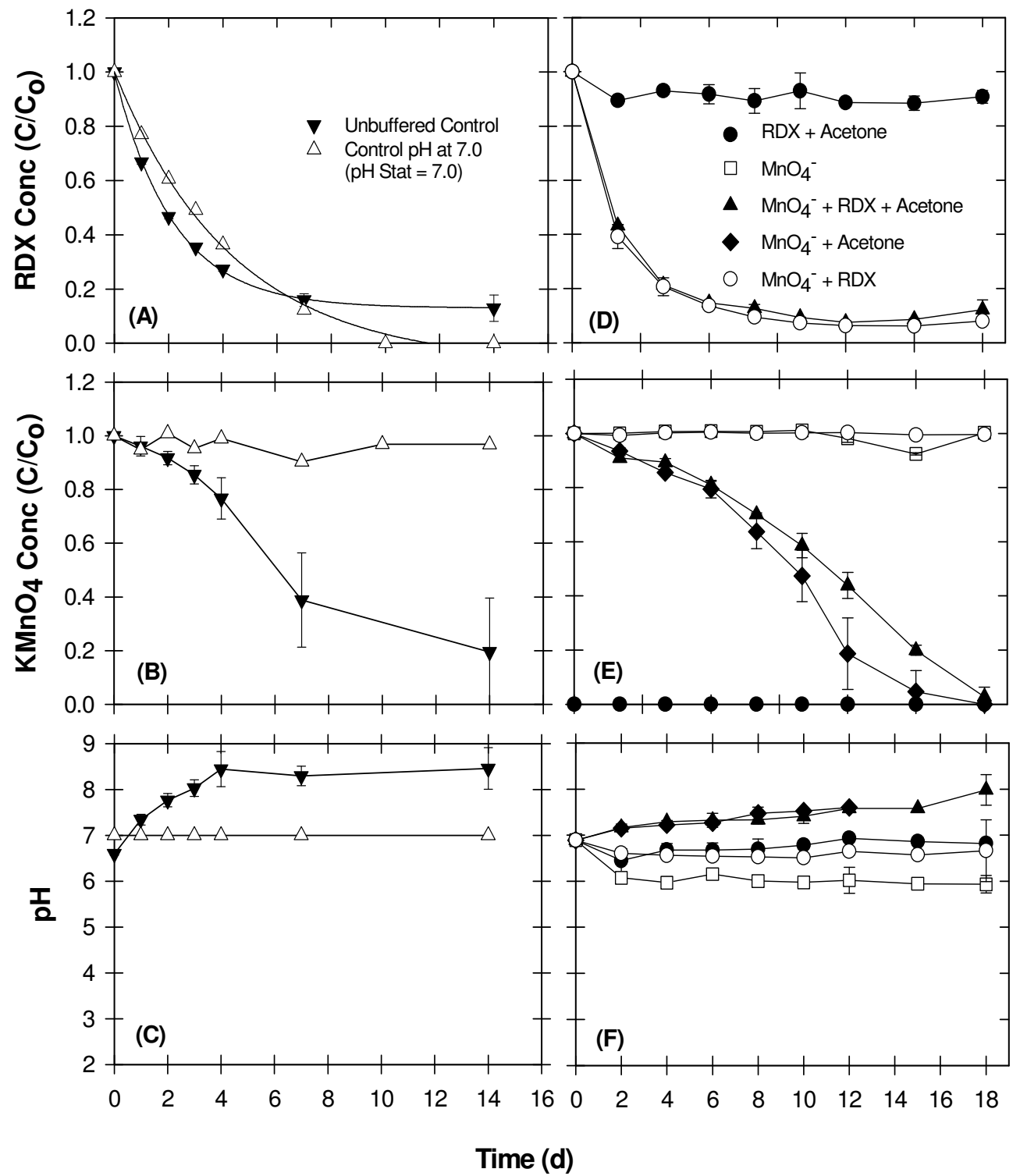

Figure S10: $(\mathrm{A}-\mathrm{C})$ Changes in $\mathrm{RDX}, \mathrm{MnO}_{4}{ }^{-}$concentration, and $\mathrm{pH}$ in the presence of acetone following treatment with $84.03 \mathrm{mM}$ of $\mathrm{MnO}_{4}^{-}$(i.e., Unbuffered control, and control $\mathrm{pH}$ at 7). (D-F) Changes in $\mathrm{RDX}, \mathrm{MnO}_{4}^{-}$concentration, and $\mathrm{pH}$ with/without acetone. Solution samples were quenched with $\mathrm{MnSO}_{4}$. Bars indicate sample standard deviations $(n=3)$. 


\section{SI-6. Kinetic Models}

While second-order expressions are commonly used to describe contaminant destruction rates by $\mathrm{MnO}_{4}^{-}$(28-32), if $\mathrm{MnO}_{4}^{-}$is in excess, the reaction can also be described by a pseudo first-order expression $(12,33)$. Like many other second-order reactions between contaminant and $\mathrm{MnO}_{4}{ }^{-}$, the general rate equation can be written as:

$$
\begin{gathered}
r=-\frac{1}{\alpha} \frac{d[R D X]}{d t}=k[R D X]^{\infty}\left[\mathrm{MnO}_{4}^{-}\right]^{\beta} \\
r=k_{o b s}[R D X]^{\alpha} \\
k_{o b z}=k\left[\mathrm{MnO}_{4}^{-}\right]^{\beta}
\end{gathered}
$$

Where $\alpha$ is a reaction order with respect to $\operatorname{RDX} \beta$ is a reaction order with respect to $\mathrm{MnO}_{4}{ }^{-}, r$ is a reaction rate, $k$ is a second-order rate constant, and $k_{\text {obs }}$ is a pseudo-order rate constant. By varying the initial concentration of $\mathrm{MnO}_{4}{ }^{-}$and measuring $k_{o b s}$ by fitting the results into a pseudo first-order equation by regression analysis using computer software SigmaPlot Version 10.0 (34), the value of $\beta$ with respect to $\mathrm{MnO}_{4}{ }^{-}$ can be obtained by a log-log form of Eq. S6:

$$
\log k_{o b s}=\log k+\beta \log \left[\mathrm{MnO}_{4}^{-}\right]_{0}
$$

Likewise, by varying the initial concentration of RDX and measuring the reaction rate, the value of $\propto$ with respect to RDX can be determined by a log-log form of Eq. S5. To evaluate for the reaction rates, we used the initial reaction rate $\left(r_{o}\right)$ by approximating the tangent to the concentration time-curve (35); therefore, Eq. S5 can then be expressed as:

$$
\log r_{o}=\log k_{s b s}+\propto \log [R D X]_{0}
$$

Second-order rates $(k)$ were then derived from pseudo first-order rates $\left(k_{o b s}\right)$ by the relationship in Eq. S6. 

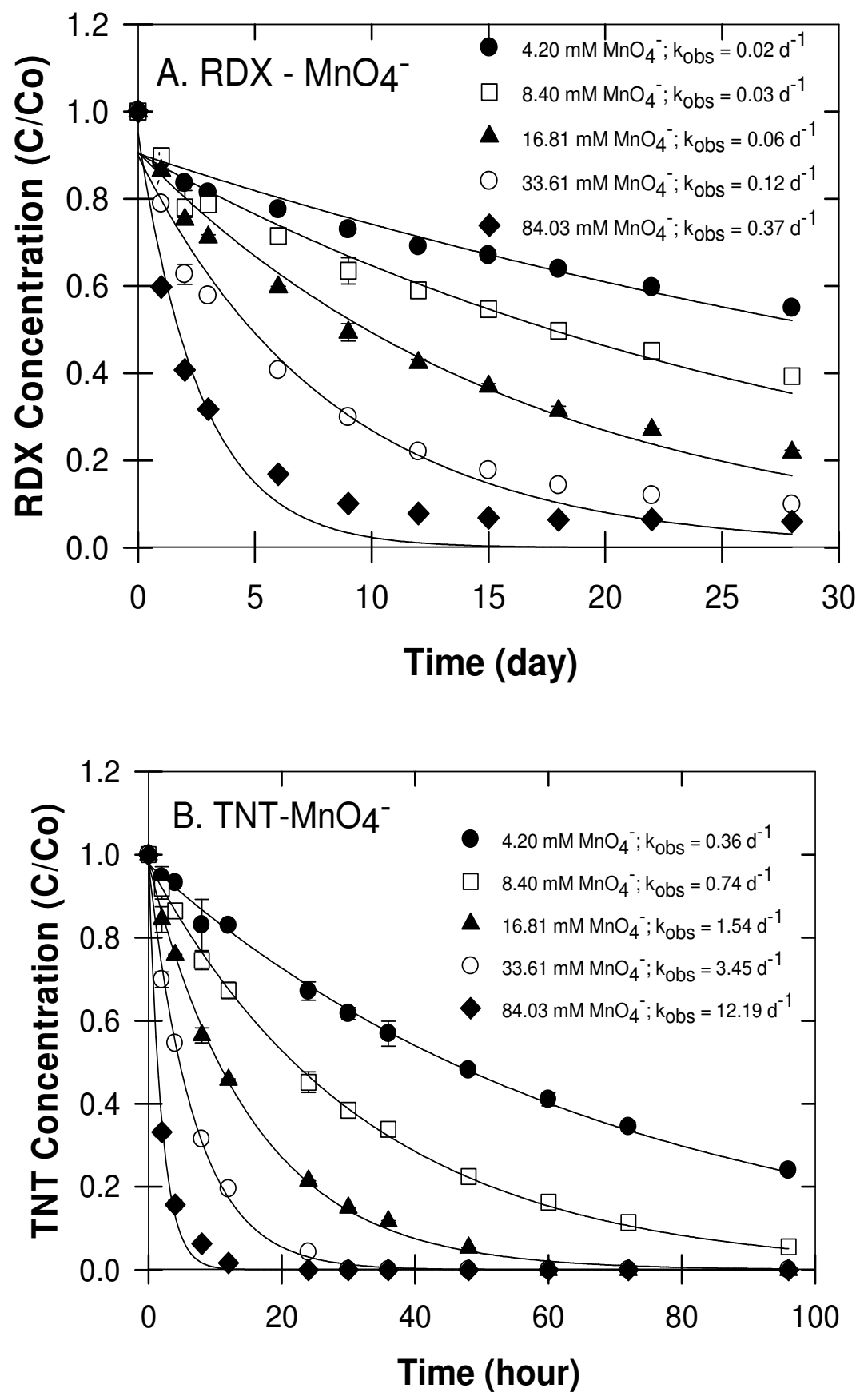

Figure S11: Loss of RDX (A) and TNT (B) when treated with various concentrations of $\mathrm{MnO}_{4}{ }^{-}$. Note differences in time scales. Bars indicate sample standard deviations $(n=3)$. 


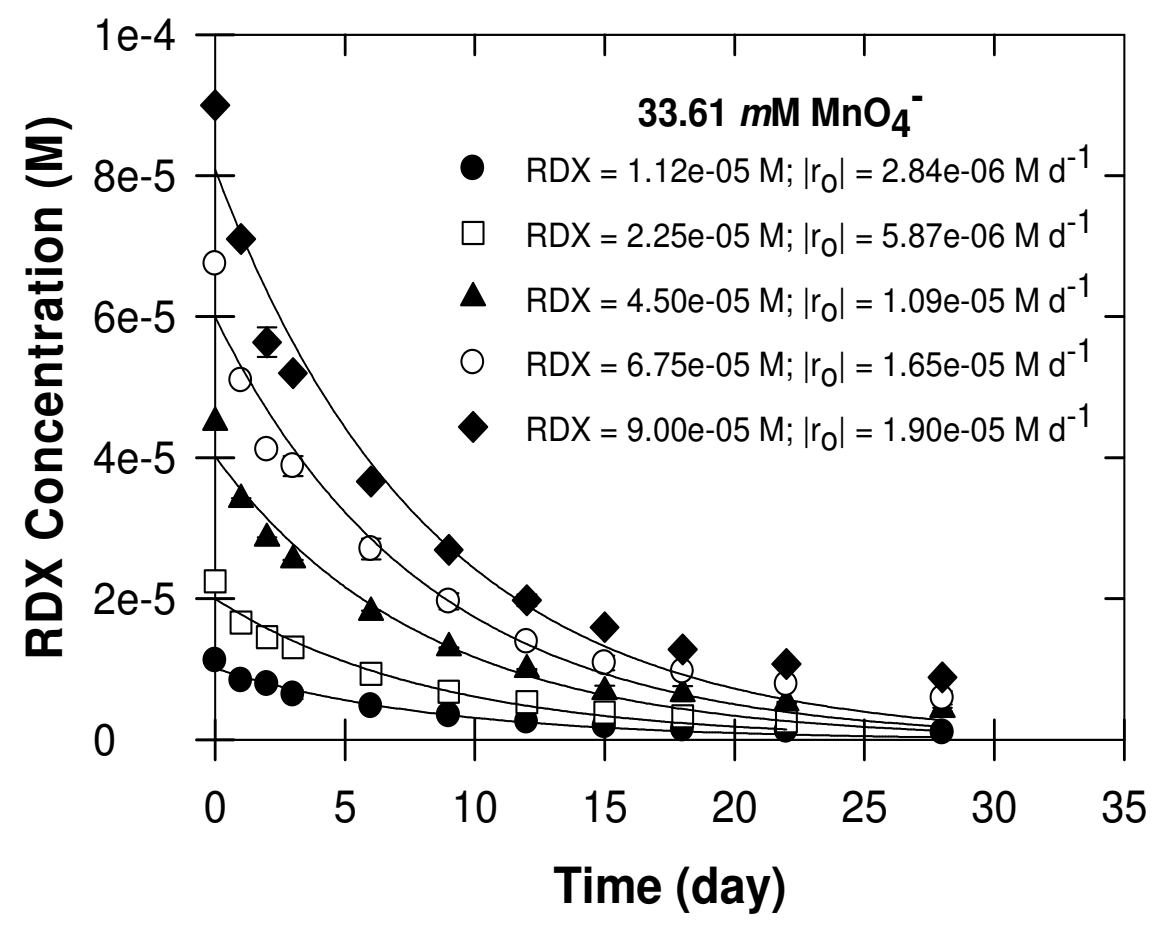

Figure S12: Loss of RDX (initial concentrations ranging from 0.01 to $0.09 \mathrm{mM}$ ) when treated with $\mathrm{MnO}_{4}{ }^{-}$at $33.61 \mathrm{mM}$. Bars indicate sample standard deviations $(\mathrm{n}=$ 3). 


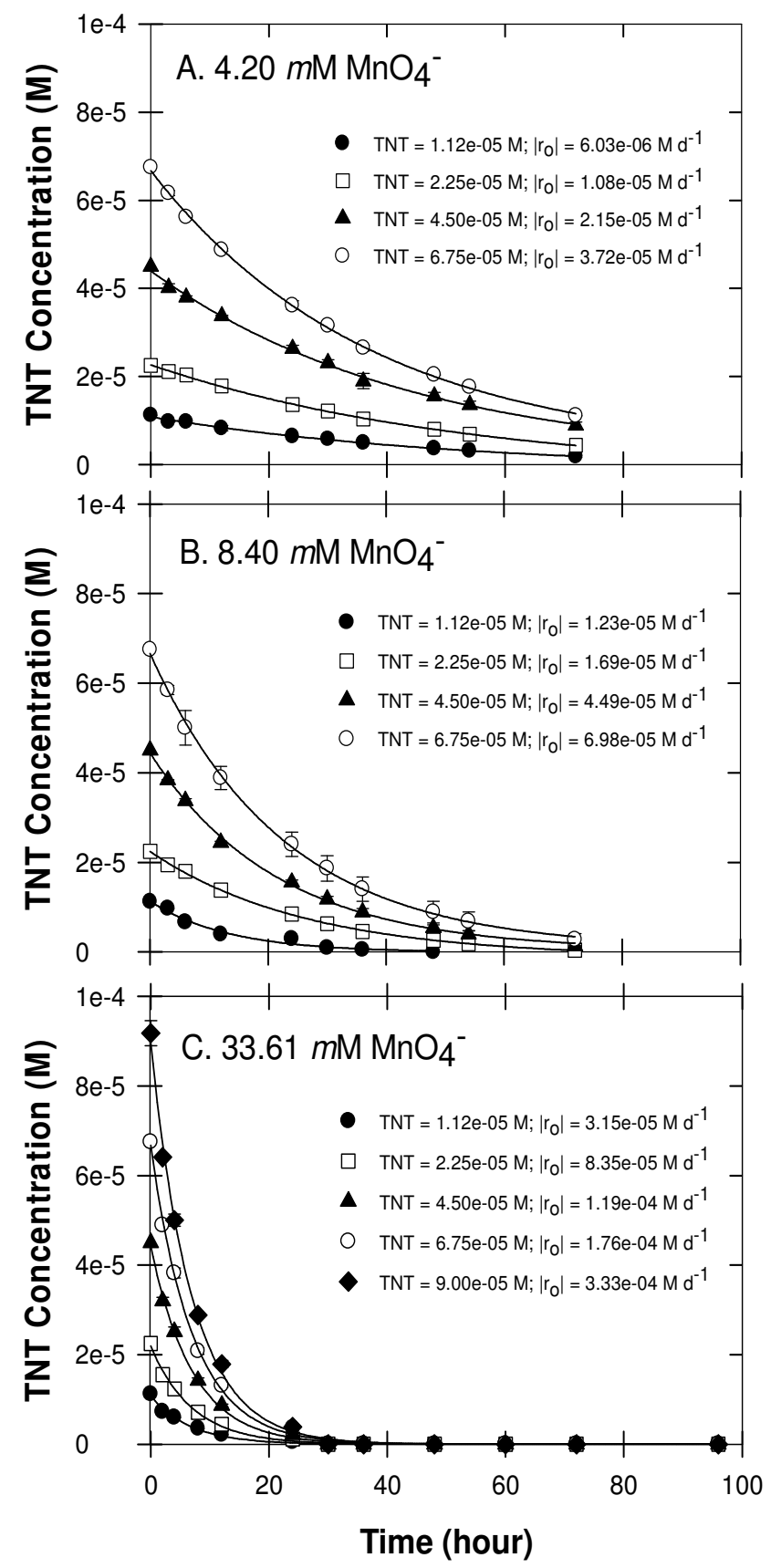

Figure S13: Loss of TNT (initial concentrations ranging from 0.01 to $0.09 \mathrm{mM}$ ) when treated with $\mathrm{MnO}_{4}{ }^{-}$at $4.20(\mathrm{~A}), 8.40(\mathrm{~B})$, or $33.61 \mathrm{mM}(\mathrm{C})$. Bars indicate sample standard deviations $(n=3)$. 

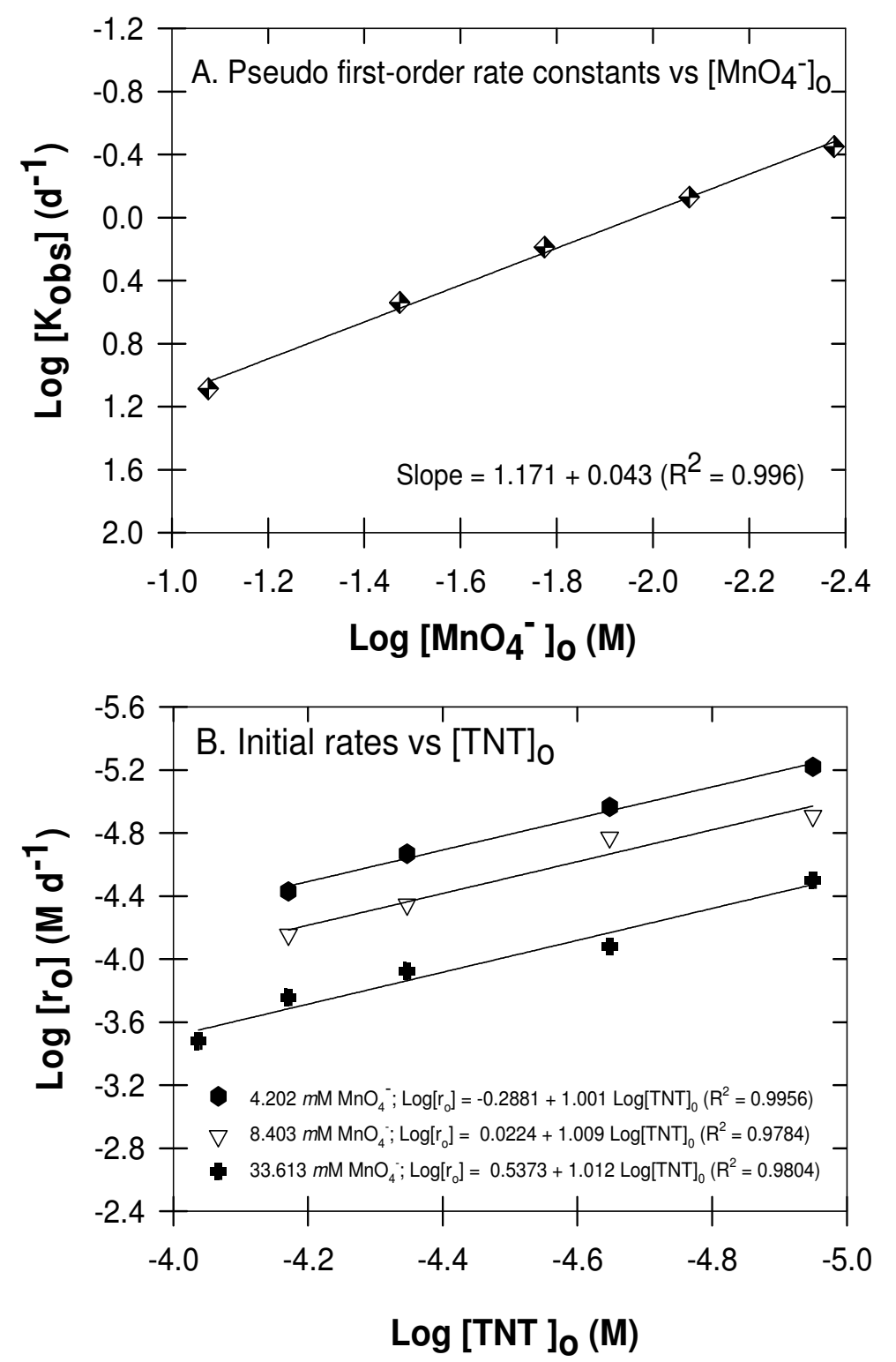

Figure S14: (A) Plot of pseudo first-order rate constants for TNT degradation vs $\left[\mathrm{MnO}_{4}{ }^{-}\right]$. Aqueous TNT $(0.09 \mathrm{mM})$ was treated with $\mathrm{MnO}_{4}{ }^{-}$ranging from 4.20 to $84.03 \mathrm{mM}$. (B) Plot of initial rates of TNT degradation vs. [TNT]。 ranging from 0.01 to $0.09 \mathrm{mM}$ when treated with $4.20,8.40$, or $33.61 \mathrm{mM} \mathrm{MnO}_{4}$. 


\section{SI-7. Temperature dependency}

In $\mathrm{RDX}-\mathrm{MnO}_{4}^{-}$temperature experiment, the pseudo first-order rates were evaluated at four different temperatures. The activation energy, $E$, can be determined using a plot of the Arrhenius equation, as follows:

$$
\ln k(T)=\ln A-\frac{E}{R T}
$$

Where $A$ is the empirical Arrhenius factor or pre-exponential factor; $R$ is gas constant (8.314 $\mathrm{J} / \mathrm{K} \cdot \mathrm{mol})$; and $T$ is the absolute temperature $(\mathrm{K})$. The logarithm of the secondorder rate constants $(k)$ are plotted against the reciprocal temperature $(1 / T)$ to determine the Arrhenius factor $A$ and the $E / R$ value from its linear least-squares fit $(20$, 36-37). 
Table S2. Temperature Dependency of Kinetic Rates for Treatment of 0.02 mM RDX with $4.20 \mathrm{mM} \mathrm{MnO}_{4}^{-}$

$\begin{array}{cccccc}\mathrm{T} & \mathrm{K}_{\mathrm{RDX} 1}{ }^{a} & \mathrm{k}_{\mathrm{RDX} 2}{ }^{a, b} & \mathrm{k}_{\mathrm{RDX} 2}{ }^{a} & \mathrm{Ln} \mathrm{K}_{\mathrm{RDX} 2}{ }^{a} & 1 / \mathrm{T} \\ \left({ }^{\circ} \mathrm{C}\right) & \left(\mathrm{d}^{-1}\right) & \left(\mathrm{L} \mathrm{mol}^{-1} \mathrm{~d}^{-1}\right) & \left(\mathrm{L} \mathrm{mol}^{-1} \mathrm{~min}^{-1}\right) & & (1 / \mathrm{K}) \\ 20 & 0.02 & 3.52 & 0.00 & -6.01 & 0.0034 \\ & (0.00) & (0.13) & (0.00) & (0.04) & \\ 35 & 0.06 & 14.22 & 0.01 & -4.62 & 0.0032 \\ & (0.00) & (0.21) & (0.00) & (0.01) & \\ 50 & 0.35 & 84.21 & 0.06 & -2.84 & 0.0031 \\ & (0.01) & (2.22) & (0.00) & (0.03) & \\ 65 & 0.89 & 212.65 & 0.15 & -1.91 & 0.0030 \\ & (0.03) & (7.16) & (0.01) & (0.03) & \end{array}$

$a$ Parenthetic values represent standard error of estimates. $b \mathrm{k}_{\mathrm{RDX} 2}=\mathrm{k}_{\mathrm{RDX} 1} / \mathrm{C}_{\mathrm{MnO4}}$ 


\section{SI-8. Single electron transfer versus hydride (or hydrogen atom) removal}

Based on supporting literature (38-40), two key ideas emerge:

1) Two different mechanisms are observed in amino oxidations

a) single-electron transfer (SET) at the amine nitrogen and

b) hydride (or hydrogen) abstraction from the carbon;

2) The electron density on the amine nitrogen determines the operative mechanism.

Specifically, electron-poor amines or those with resonance stabilized intermediates tend to be oxidized by hydride abstraction. When these specific principles and the principles of organic oxidation chemistry are applied to RDX, the problem simplifies somewhat. For instance, there are only four distinct sites for oxidation of RDX: an oxygen atom, a nitro nitrogen atom, an amine nitrogen atom, or a carbon. This is illustrated below.

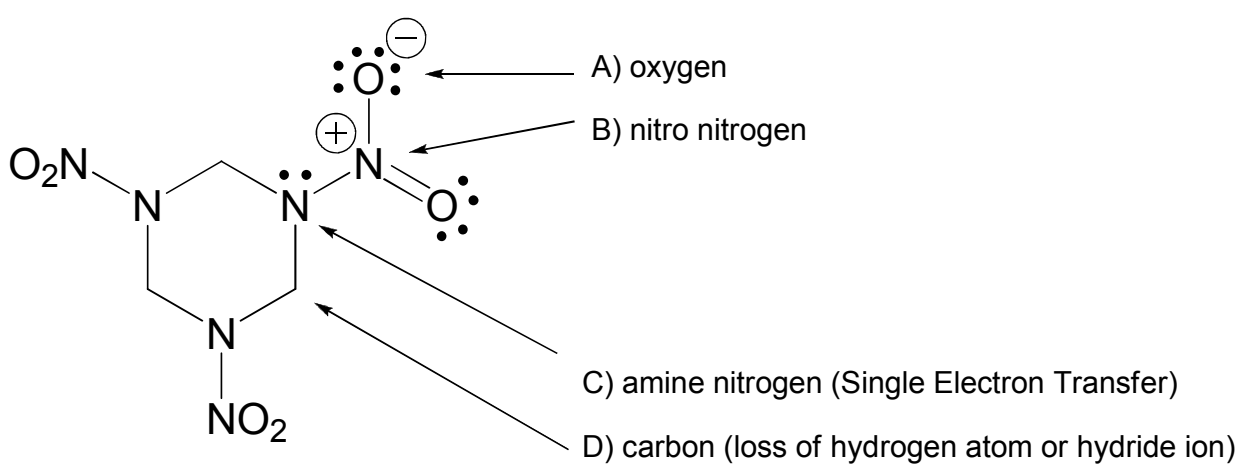

Figure S15: Possible sites for oxidation of RDX.

Oxidation at the oxygen atom or a nitro nitrogen atom would give extremely unstable intermediates since they place positive charge on electronegative oxygen or 
an already electron deficient nitro group nitrogen, respectively. The only two reasonable sites for oxidation of $\mathrm{RDX}$ remaining are the exact two options carefully studied by the cited authors (38-40). That is, oxidation at the amine nitrogen (by SET) or oxidation at the carbon (by hydride abstraction, see $\mathrm{S} 16, \mathrm{~S} 17$ below).<smiles>O=[N+]([O-])N1CCN([N+](=O)[O-])N([N+](=O)[O-])C1</smiles><smiles>O=[N+]([O-])N1CN([O-])CN([N+](=O)[O-])C1</smiles>
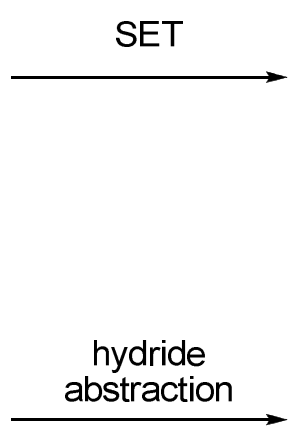
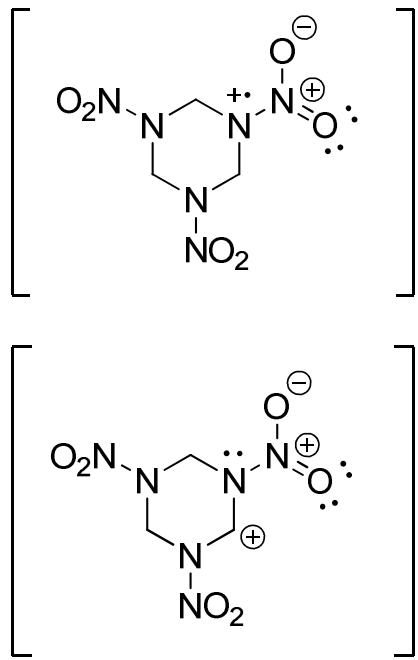

Figure S16: Overall comparison of SET versus hydride abstraction of RDX.

Because the amino nitrogens in RDX are extremely electron-poor, the hydride loss will tend to dominate the reaction. This is probably because the intermediate resulting from an initial single-electron transfer would produce an intermediate having two positive charges on the adjacent nitrogen atoms, as shown above. Such an intermediate would be much less stable than the proposed carbocation which maximizes the distance of the two positive charges from each other, and places one of them on the more electropositive carbon atom. 
A

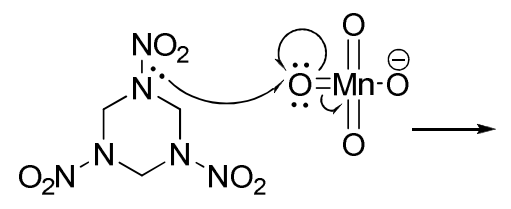<smiles>O=[N+]([O-])N1CN([N+](=O)[O-])C[N+]([O-])([N+](=O)[O-])C1</smiles><smiles>O=[N+]([O-])O[Na]</smiles>

B

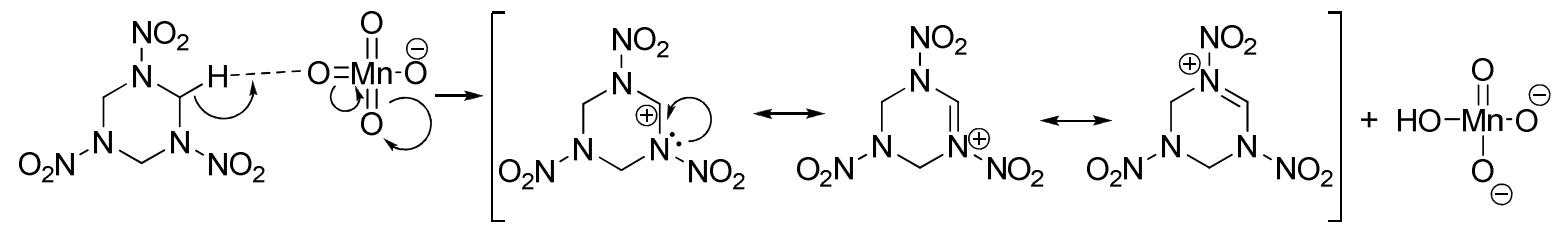

Figure S17: A comparison of initial first steps via single electron transfer $(A)$ versus hydride removal $(\mathrm{B})$.

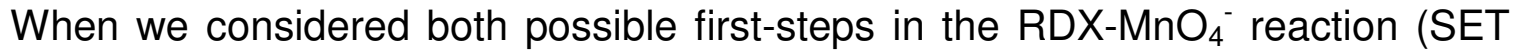
vs. Hydride loss, Fig. S15), we believe the strongly electron-withdrawing nitro groups would tend to destabilize any cation intermediate. This destabilizing effect, however, would be minimized for the carbocation intermediate formed via hydride abstraction (Fig S17B) compared to the aminium ion formed by SET (Fig. S17A) because: 1) the carbocation is further from the nitro group than the aminium ion and is therefore less destabilized by inductive effects, 2) carbon is more electropositive than nitrogen, and thus less destabilized by the cation, 3) resonance stabilization for the carbocation can occur but is completely absent for the aminium intermediate. These theoretical explanations are supported by the experimental observations that $1^{\circ}, 2^{\circ}$ and $3^{\circ}$ alkylamines having all their electron density isolated on the nitrogen tend to be oxidized by SET (38-39), while amines with resonance distributed electron density like benzylamine clearly undergo loss of hydride (or hydrogen atom) (40). Thus, theory and experiment indicate that the carbocation intermediate will be more stable and therefore formed more quickly than the aminium cation intermediate in RDX. 


\section{SI-9. Proposed RDX degradation via proton abstraction}

\section{$\mathrm{RDX}-\mathrm{MnO}_{4}^{-}$(hydrolysis and oxidation)}

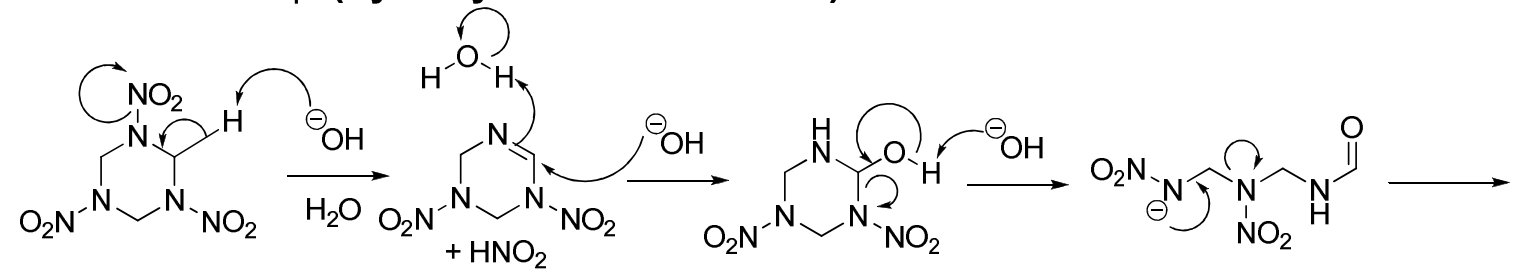

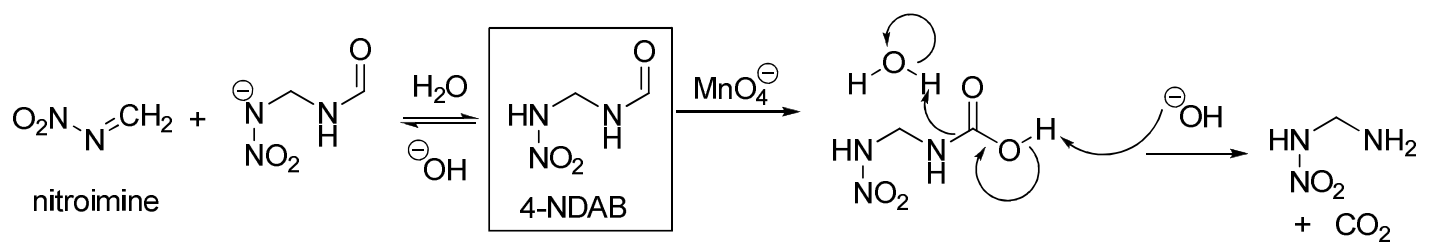

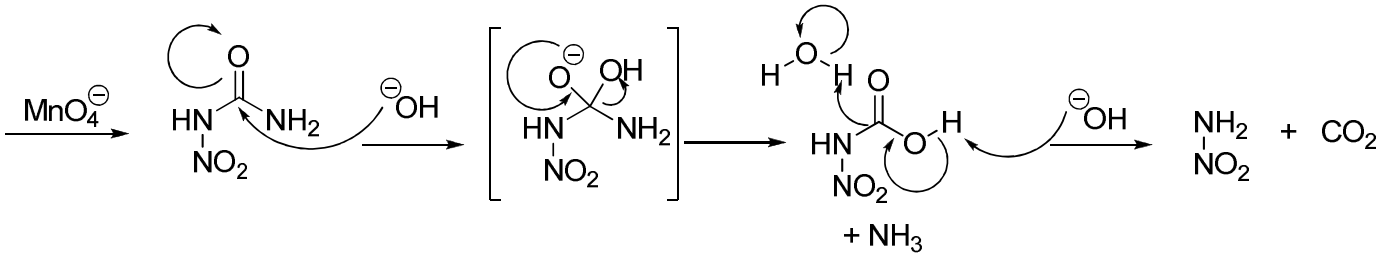

\section{Nitroimine $-\mathrm{MnO}_{4}^{-}$(hydrolysis and oxidation)}

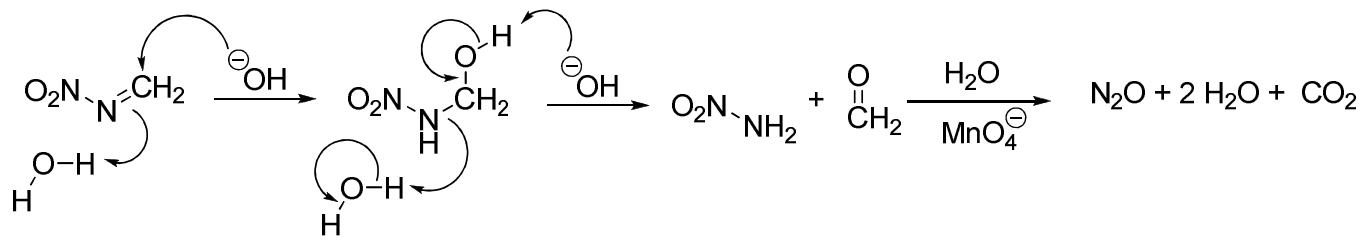

Overall reaction $\left(\mathrm{HNO}_{2}\right.$ further oxidized to $\left.\mathrm{HNO}_{3}\right)$<smiles>O=[N+]([O-])N1CN([N+](=O)[O-])CN([N+](=O)[O-])C1</smiles>

Figure S18: Proposed RDX degradation via proton abstraction and oxidation via $\mathrm{MnO}_{4}{ }^{-}$ under alkaline $\mathrm{pH}$. 


\section{SI-10. References}

(1) Ross, P.J.; Martin, A.E. A rapid procedure for preparing gas samples for nitrogen-15 determination. Analyst 1970, 95(1134), 817-822.

(2) Sada, E.; Kumazawa, H.; Hayakawa, N. Absorption of NO in aqueous solutions of $\mathrm{KMnO}_{4}$. Chem. Eng. Sci. 1977, 32(10), 1171-1175.

(3) Brogren, C.; Karlsson, H.T.; Bjerle, I. Absorption of NO in an alkaline solution of $\mathrm{KMnO}_{4}$. Chem. Eng. Technol. 1997, 20(6), 396-402.

(4) Xianshe, F.; John, I.; Paula, T. Scavenging of nitric oxide and nitrogen dioxide by reactive absorption. Fluid/Part. Sep. J. 2003, 15(2), 171-174.

(5) Nelson, D.W.; Bremner, J.M. Gaseous products of nitrite decomposition in soils. Soil. Biol. Biochem. 1970, 2(3), 203-215.

(6) Tedesco, M.J.; Keeney, D.R. Determination of (nitrate+nitrite)- $\mathrm{N}$ in alkaline permanganate solutions. Commun. Soil. Sci. Plant Anal. 1972, 3(4), 339-344.

(7) Bundy, L.G.; Bremner, J.M. Determination of ammonium-N and nitrate-N in acid permanganate solution used to absorb ammonia, nitric oxide, and nitrogen dioxide evolved from soils. Commun. Soil Sci. Plant Anal. 1973, 4(3), 179-184.

(8) Smith, C.J.; Chalk, P.M. Determination of nitrogenous gases evolved from soild in closed systems. Analyst 1979, 104(1239), 538-544.

(9) Flasarova, M.; Novak, J.; Ulrich, R.; Vyhlidka, P. Determination of nitrites in mixtures with nitrates by using a nitrate-selective electrode. Chem. Listy 1986, 80(3), 328-331.

(10) Perez-Benito, F.J.; Arias, C.; Brillas, E. A kinetic study of the autocatalytic permanganate oxidation of formic acid. Int. J. Chem. Kinet. 1990, 22(3), 261-287.

(11) Root, D.K. In-situ chemical oxidation of chlorinated hydrocarbons in the presence of radionuclides. Presented at WM'03 Conference [Online], Tucson, AZ, 
February 23-27, 2003. WM Symposia Website. http://www.wmsym.org/archives/ 2003/pdfs/184.pdf (accessed Feb 25, 2008).

(12) Adam, M.L.; Comfort, S.D.; Snow, D.D. Remediating RDX-contaminated ground water with permanganate: Laboratory investigations for the Pantex perched aquifer. J. Environ. Qual. 2004, 33(6), 2165-2173.

(13) Adam, M.L.; Comfort, S.D.; Snow, D.D.; Cassada, D.; Morley, M.C.; Clayton, W. Evaluating ozone as a remedial treatment for removing RDX from unsaturated soils. J. Environ. Eng. 2006, 132(12), 1580-1588.

(14) Ladbury, J.W.; Cullis, C.F. Kinetics and mechanism of oxidation by permanganate. Chem. Rev. 1958, 58(2), 403-438.

(15) Kanungo, S.B.; Parida, K.M.; Sant, B.R. Studies on $\mathrm{MnO}_{2}$-III. The Kinetics and the mechanism for the catalytic decomposition of $\mathrm{H}_{2} \mathrm{O}_{2}$ over different crystalline modifications of $\mathrm{MnO}_{2}$. Electrochim. Acta 1981, 26(8), 1157-1167.

(16) Lee, J.Y. Method for reductive degradation of chlorinated organic compounds using a reductive intermediate produced by decomposition of hydrogen peroxide under the existence of a manganese oxide catalyst. Korean Patent 036875. 2006.

(17) Shah, M.M. Method for digesting a nitro-bearing explosive compound. U.S. Patent 6,118,039. September 12, 2000.

(18) Zhang, W.; Zhang, Y.; Yang, Z.; Hu, L.; Ye, L. Study on decomposition of methylene blue in the presence of $\mathrm{H}_{2} \mathrm{O}_{2}$ with nanostructured $\mathrm{Mn}_{2} \mathrm{O}_{3}$ as catalysts. Hefei Gongye Daxue Xuebao, Ziran Kexueban. 2005, 28(11), 1435-1439.

(19) Gates-Anderson, D.D.; Siegrist, R.L.; Cline, S.R. Comparison of potassium permanganate and hydrogen peroxide as chemical oxidants for organically contaminated soils. J. Environ. Eng. 2001, 127(4), 337-347.

(20) Heilmann, H.M.; Wiesmann, U.; Stenstrom, M.K. Kinetics of the alkaline 
hydrolysis of high explosives RDX and HMX in aqueous solution and adsorbed to activated carbon. Environ. Sci. Technol. 1996, 30(5), 1485-1492.

(21) Jackson, R.G.; Rylott, E.L.; Fournier, D.; Hawari, J.; Bruce, N.C. Exploring the biochemical properties and remediation applications of the unusual explosivedegrading P450 system XpIA/B. Proc. Natl. Acad. Sci. USA. 2007, 104(43), 16822-16827.

(22) Suthersan S.; Ganczarcczyk, J. Inhibition of nitrite oxidation during nitrification. Water Pollut. Res. 1986, 21(2), 257-266.

(23) Cleemput, O.V.; Samater, A.H. Nitrite in soils: Accumulation and role in the formation of gaseous N compounds. Fert. Res. 1996, 45(1), 81-89.

(24) Balakrishnan, V.K.; Halasz, A.; Hawari, J. Alkaline hydrolysis of the cyclic nitramine explosives RDX, HMX, and CL-20: New insights into the degradation pathyways obtained by the observation of novel intermediates. Environ. Sci. Technol. 2003, 37(9), 1838-1843.

(25) Chokejaroenrat, C. Laboratory and pilot-scale investigations of RDX treatment by permanganate. M.S. Thesis, University of Nebraska-Lincoln, Lincoln, NE, 2008.

(26) Yan, Y.E.; Schwartz, F.W. Kinetics and mechanisms for TCE oxidation by permanganate. Environ. Sci. Technol. 2000, 34(12), 2535-2541.

(27) Li, Z.M.; Comfort, S.D.; Shea, P.J. Destruction of 2,4,6-trinitrotoluene (TNT) by Fenton oxidation. J. Environ. Qual. 1997, 26(2), 480-487.

(28) Yan, Y.E.; Schwartz, F.W. Oxidative degradation and kinetics of chlorinated ethylenes by potassium permanganate. J. Contam. Hydrol. 1999, 37(3-4), 343365.

(29) Huang, K.; Hoag, G.A.; Chheda, P.; Woody, B.A.; Dobbs, G.M. Kinetic study of oxidation of trichloroethylene by potassium permanganate. Environ. Eng. Sci. 1999, 16(4), 265-274. 
(30) Huang, K.; Hoag, G.A.; Chheda, P.; Woody, B.A.; Dobbs, G.M. Oxidation of chlorinated ethenes by potassium permanganate: A kinetics study. J. Hazard. Mater. 2001, 87(1-3), 155-169.

(31) Siegrist, R.L.; Urynowicz, M.A.; West, O.A.; Crimi, M.L.; Lowe, K.S. Principles and practices of in-situ chemical oxidation using permanganate; Battelle Press: Columbus, OH, 2001.

(32) Waldemer, R.H.; Tratnyek, P.G. Kinetics of contaminant degradation by permanganate. Environ. Sci. Technol. 2006, 4O(3), 1055-1061.

(33) Siegrist, R.L.; Urynowicz, M.A.; Crimi, M.L.; Lowe, K.S. Genesis and effects of particles produced during in-situ chemical oxidation using permanganate. J. Environ. Eng. 2002, 128(11), 1068-1079.

(34) SPSS. SigmaPlot for Windows Version 10.0: Chicago, IL, 2006.

(35) Casado, J.; Lopez-Quintela, M.A.; Lorenzo-Barral, F.M. The initial rate method in chemical kinetics: Evaluation and experimental illustration. J. Chem. Educ. 1986, 63(5), 450-452.

(36) Karakaya, P.; Mohammed, S.; Christos, C.; Steve, N.; Wendy, B. Aqueous solubility and alkaline hydrolysis of the novel high explosive hexanitrohexaazaisowurtzitane (CL-20). J. Hazard. Mater. 2005, 120(1-3), 183191.

(37) Benson, S.W. The Foundations of chemical kinetics; Krieger Publishing Co.: Florida, 1982; pp 66-68.

(38) Rosenblatt, D.H.; Davis, G.T.; Hull, L.A.; Forberg, G.D. Oxidations of amines. V. Duality of mechanism in the reactions of aliphatic amines with permanganate $\mathrm{J}$. Org. Chem. 1968, 33(4), 1649-1650.

(39) Mata-Perez, F.; Perez-Benito, J.F. Kinetics and mechanisms of oxidation of methylamine by permanganate ion. Can. J. Chem. 1987, 65(10), 2373-2379. 
(40) Wei, M.; Stewart, R. The mechanisms of permanganate oxidation. VIII. Substituted benzylamines J. Am. Chem. Soc. 1966, 88(9), 1974-1979. 